\title{
INFECÇÃO DE CORRENTE SANGUÍNEA ASSOCIADA AO USO DE PICC EM NEONATOS: CONHECIMENTO DE GRADUANDOS DE ENFERMAGEM SOBRE OS FATORES RELACIONADOS E ESTRATÉGIAS UTILIZADAS PARA A PREVENÇÃO
}

\author{
Isabelly Motta Figueredo da Silva ${ }^{1}$ \\ Gabriela Losano Pais Barbosa ${ }^{2}$ \\ Maria Aparecida Xavier Moreira da Silva ${ }^{3}$
}

RESUMO: Este estudo busca obter maior conhecimento sobre as ações e estratégias utilizadas pelo enfermeiro para a prevenção de Infecção de Corrente Sanguínea associada ao uso de PICC em neonatos. Objetivo: O objetivo do estudo é descrever o conhecimento dos graduandos de enfermagem sobre os fatores relacionados à ICS associada ao uso de PICC em neonatos e as estratégias utilizadas para a prevenção. Método: Trata-se de uma pesquisa descritiva, transversal e com abordagem qualitativa que foi realizada com graduandos de enfermagem do 6으 ao Io da Universidade de Mogi das Cruzes, em São Paulo, Brasil. Resultados e discussão: Para compor este estudo, os dados sociodemográficos foram coletados para entendermos melhor o público participante. Foram convidados 22 graduandos do curso de enfermagem ao todo, sendo 81,82 do sexo feminino, e $18,18 \%$ do sexo masculino, com idade variadas, de até 25 anos (68,18\%), 25 a 35 anos (18,18\%), 35 a 45 anos (9,09\%) e de 45 anos em diante (4,55\%). Conforme os resultados obtidos por meio de questionário separado por temáticas, salientamos que, os alunos entrevistados demonstraram concordância com que diz a literatura sobre a importância da capacitação para passagem e manutenção do PICC e demais cuidados que objetivam a prevenção de ICS associada. Conclusão: Os dados coletados e seus respectivos resultados demonstram um conhecimento satisfatório dos graduandos sobre as questões aplicadas, mostrando que o objetivo deste estudo foi alcançado.

Palavra-chave: Enfermagem neonatal. Cateter Central de Inserção Periférica. Cateterismo Periférico. Infecção de Corrente Sanguínea.

ABSTRACT: This study seeks to obtain greater knowledge about the actions and strategies used by nurses for the prevention of Bloodstream Infection associated with the use of PICC in neonates. Objective: The aim of the study is to describe the knowledge of

\footnotetext{
${ }^{1}$ Graduanda em Enfermagem pela Universidade de Mogi das Cruzes, SP Orcid iD: https://orcid.org/ooooooor-7327-1096

${ }^{2}$ Graduanda em Enfermagem pela Universidade de Mogi das Cruzes, SP. Orcid iD: https://orcid.org/oooo0002-3993-1860

${ }^{3}$ Professora, Enfermeira e Mestre em Políticas Públicas pela Universidade de Mogi das Cruzes, SP. Orcid iD: https://orcid.org/oooo-ooo2-7851-4349
} 
nursing students about factors related to ICS associated with the use of PICC in neonates and the strategies used for prevention. Method: This is a descriptive, cross-sectional study with a qualitative approach that was carried out with nursing students from the 6th to the roth period of the Undergraduate Nursing Course at the University of Mogi das Cruzes, in São Paulo, Brazil. Results and discussion: To compose this study, sociodemographic data were collected to better understand the participating public. A total of 22 undergraduate nursing students were invited, 81.82 females, and $18.18 \%$ males, with varying ages, up to 25 years old (68.18\%), 25 to 35 years old (18, 18\%), 35 to 45 years (9.09\%) and from 45 years onwards $(4.55 \%)$. According to the results obtained through a questionnaire separated by themes, we emphasize that the students interviewed showed agreement with what the literature says about the importance of training for passing and maintaining the PICC and other care aimed at preventing associated ICS. Conclusion: The collected data and their respective results demonstrate a satisfactory knowledge of undergraduates about the applied questions, showing that the objective of this study was achieved.

Descriptors: Neonatal nursing. Peripherally Inserted Central Catheter. Peripheral Catheterization. Bloodstream Infection.

\section{INTRODUÇÃO}

Atualmente, é possível observar e usufruir dos diversos avanços tecnológicos presentes na área da neonatologia e que são aplicados também nas Unidades de Terapia Intensiva Neonatais (UTIN), contribuindo assim para o aumento da taxa de sobrevivência dos recém-nascidos (RN) pré-termos ou de baixo-peso. (RANGEL et al., 2016).

Ao ser considerada como ambiente exclusivo para o tratamento de recém-nascidos de alto risco, a UTIN exige uma equipe de saúde bem prepara e capacitada para desenvolver as atividades da unidade corretamente e que sustente a complexidade das mesmas. (LUI et al., 2018).

Para Rangel et al. (2019, p. 279), na "assistência de enfermagem em neonatologia" observa-se "a necessidade de acesso venoso seguro e duradouro para administração de antibióticos, hidratação venosa, nutrição parenteral, drogas vasoativas entre outras".

De acordo com Borghesan et al. (2017):

O cateter venoso central de inserção periférica (PICC) é um dispositivo intravenoso longo e flexível, inserido por meio de uma punção de veia periférica, progride com a ajuda do fluxo sanguíneo até atingir a localização central, ou seja, veia cava superior (VCS) ou junção cavo-atrial se inseridos pelos membros superiores; e veia cava inferior (VCI), se inserido pelos membros inferiores. (BORGHESAN et al., 2017, p. I). 
O PICC vem sendo amplamente utilizado nas instituições de saúde, inclusive nos recém-nascidos, devido:

[...] por possuir as vantagens como: permanecer por período prolongado, não ter prejuízo vascular, ser inserido à beira do leito, possuir menor risco de infecção em relação a outros dispositivos vasculares centrais, melhorar a hemodiluição de drogas, minimizar procedimentos invasivos, o estresse e o desconforto do neonato (RANGEL et al., 2019, p. 279).

A utilização do PICC se iniciou no Brasil a partir de 1990 e os enfermeiros(as) são os profissionais mais envolvidos no manejo deste dispositivo. A atividade "foi regulamentada pelo Conselho Federal de Enfermagem, conforme descreve a Resolução no. 258/200I, artigos Iํ e 2ㅇ․ Deste modo, o enfermeiro é o profissional respaldado legalmente para inserir, manipular e remover o CCIP, quando este for indicado". (BORGHESAN et al., 2017, p. 2; LUI et al., 2018, p. 2).

Embora as vantagens sejam notáveis, ainda é possível citar que existem algumas complicações relacionadas à inserção, manutenção e remoção do dispositivo, mesmo que em uma menor frequência se comparado a outros cateteres centrais. Desta forma, o PICC demanda cuidados mais específicos para que haja sucesso no procedimento, como o controle eficaz da dor, utilização de métodos que promovam melhor visualização do cateter para que se possa posicioná-lo corretamente, além das técnicas para evitar complicações e infecções advindas do dispositivo. (RANGEL et al., 2016).

Para Costa et al. (2016, p. 162) "uma das complicações mais frequentes, geradora de custos e sofrimento para o recém-nascido e sua família, além de aumento significativo da morbidade e mortalidade em recém-nascidos em unidades de terapia intensiva neonatal” tem sido "a infecção de corrente sanguínea associada ao cateter".

Os autores, Costa et al. (2016) ressaltam que os principais fatores de risco para infecção em neonatologia estão associados à manipulação constante e à exposição de inúmeros "procedimentos invasivos, como punções venosas e ventilação mecânica" aos quais os recém-nascidos internados em UTIN estão sujeitos, tornando-os susceptíveis às infecções. (COSTA et al., 2016, p. I66).

Os pacientes que utilizam PICC necessitam de contínua avaliação do cuidado em todas as etapas do processo. Diante disso, a Sistematização da Assistência de Enfermagem (SAE) apresenta-se como uma ferramenta gerencial importante para o planejamento, execução e controle desse cuidado. A aplicação da SAE é fundamental para o desenvolvimento do processo de terapia intravenosa, pois se 
encontra fundamentada em protocolos institucionais e evidências científicas, viabilizando a organização do cuidado e o respaldo legal para as ações de enfermagem. (LUI et al., 2018, p. 6).

Segundo Costa et al. (2016), as ICS associadas ao uso de cateteres intravenosos atingem nos primeiros dias de vida grande parte dos recém-nascidos, em especial, os prematuros de baixo peso, gerando problemas ao neonato, a sua rede familiar e a instituição de saúde que, terá de desempenhar um tempo de internação mais prolongado e uso de recursos terapêuticos mais aprimorados, além de, ocorrer o aumento das chances de morbidade e de mortalidade nessa população.

Diante do exposto, este estudo se justifica pela busca de maior conhecimento sobre as ações e estratégias utilizadas pelo enfermeiro para a prevenção de Infecção de Corrente Sanguínea associada ao uso de PICC em neonatos. De acordo com as Diretrizes Curriculares Nacionais (DCNs) descritas no Parecer no CNE/CES 1.133/2001 para o Curso de Graduação em Enfermagem, a formação do enfermeiro é generalista, devendo este ser qualificado "com base no rigor científico e intelectual [...]" e, no entendimento dessa premissa, o graduando de enfermagem deve desenvolver conhecimento técnico-científico que o torne apto à atuar em qualquer área assistencial (BRASIL, 200I).

As DCNs para o Curso de Graduação em Enfermagem também descrevem que o graduando deve desenvolver, ao longo do seu processo de ensino-aprendizagem, seis (o6) competências gerais e trinta e três (33) competências específicas. Dentre as competências gerais, nos chama a atenção e reflexão a primeira competência que é a Atenção à Saúde, onde se descreve que o graduando de enfermagem deve estar apto "a desenvolver ações de prevenção, promoção, proteção e reabilitação da saúde, tanto em nível individual quanto coletivo" $e$, no campo do desenvolvimento das competências específicas é o item que descreve "intervir no processo de saúde-doença responsabilizando-se pela qualidade da assistência/cuidado de enfermagem em seus diferentes níveis de atenção à saúde, com ações de promoção, prevenção, proteção e reabilitação à saúde, na perspectiva da integralidade da assistência”.

Desta forma, se justifica a realização dessa pesquisa, uma vez que o graduando, tendo em vista uma formação generalista, poderá atuar na área de enfermagem neonatal, devendo este estar apto a planejar a assistência de enfermagem para prevenção e controle de ICS associada ao uso de PICC em neonatos. 
Conforme a contextualização da temática apresentada, levantou-se a hipótese de que o graduando de enfermagem, com formação generalista, está desenvolvendo ou desenvolveu em seu processo de ensino-aprendizagem conhecimentos básicos que lhe permitam identificar os principais fatores relacionados à ICS associados ao uso de PICC em neonatos e, identificando estes fatores, sabe descrever as estratégias e ações utilizadas como medidas de prevenção para a ICS.

Como questões norteadoras desta pesquisa, tem-se: Qual o conhecimento dos graduandos de enfermagem sobre o papel do enfermeiro no planejamento da assistência de enfermagem para prevenção de ICS associada ao uso do PICC em neonatos? Quais os fatores relacionados à infecção de corrente sanguínea ICS associada ao uso de PICC em neonatos? E, quais as estratégias e ações utilizadas como medidas de prevenção para ICS associada ao uso de PICC?

Para as pesquisadoras, os graduandos de enfermagem e a enfermagem como ciência, esta pesquisa é de extrema relevância, pois, poderá fomentar o desenvolvimento do conhecimento sobre a contextualização dos cuidados de enfermagem com o PICC e, em especial, sobre as estratégias e ações utilizadas como medidas de prevenção de ICS associada ao uso de PICC em neonatos.

O objetivo do estudo é descrever o conhecimento dos graduandos de enfermagem sobre os fatores relacionados à ICS associada ao uso de PICC em neonatos e as estratégias utilizadas para a prevenção.

\section{MÉTODO}

\section{NATUREZA DA PESQUISA}

Trata-se de uma pesquisa descritiva, transversal e com abordagem qualitativa que foi realizada com graduandos de enfermagem do 6으 ao Io $^{\circ}$ período do Curso de Graduação em Enfermagem da Universidade de Mogi das Cruzes em São Paulo, Brasil.

A pesquisa descritiva tem como objetivo "observar, registrar e descrever as características de um determinado fenômeno ocorrido em uma amostra ou população, sem, no entanto, analisar o mérito de seu conteúdo” (FONTELLES et al., 2009). 
Para Minayo (2000) a pesquisa qualitativa esclarece que esse tipo de método tem fundamento teórico e permite desvelar processos sociais ainda pouco conhecidos referentes a grupos particulares, propiciando assim, a construção de novas abordagens, revisão e criação de novos conceitos e categorias durante a investigação e Fontelles et al. (2009) descreve que um estudo transversal é muito utilizado para retratar breve período de tempo, considerando a situação de uma população em um determinado momento, descrevendo a situação em um dado momento.

A pesquisa foi realizada na Instituição de Ensino Superior (IES) denominada Universidade de Mogi das Cruzes - UMC, localizada no Município de Mogi das Cruzes, São Paulo, onde foram convidados a participar desta pesquisa 22 graduandos de enfermagem.

Foram inclusos todos os graduandos de enfermagem que já estavam cursando entre o $6^{\mathrm{o}}$ е Io $^{\mathrm{o}}$ período, tendo cursado a disciplina Enfermagem em Neonatologia e que aceitaram participar da pesquisa por meio de sua assinatura no Termo de Consentimento Livre e Esclarecido (TCLE).

Foram excluídos da pesquisa os graduandos que estiveram em regime de dependência (DP) na disciplina de Enfermagem em Neonatologia.

Foi utilizado como material o TCLE para atendimento dos princípios éticos e legais que envolvem as pesquisas com seres humanos, conforme determina a Resolução CNS no 466/2012, e o instrumento para coleta de dados denominado "Questionário" formulado em duas partes: primeira parte constituída para levantamento de dados sociodemográficos (idade, sexo, se atua como Técnico ou Auxiliar de Enfermagem, tempo de atuação, semestre em que está matriculado, se já cursou a disciplina de Enfermagem em Neonatologia, se tem regime de dependência [DP] nessa disciplina e área pretendida para especialização) e, segunda parte elaborado para contextualizar o conhecimento dos graduandos sobre o cateter central de inserção periférica (PICC), indicação de uso, condições e requisitos de preparo (tanto do enfermeiro quanto do recém-nascido), procedimento para inserção, estratégias e medidas de prevenção e controle da Infecção de Corrente Sanguínea (ICS) associada ao uso em recém-nascido. Na versão impressa do Questionário (APÊNDICE B) se tem o7 (sete) questões sociodemográficas e 13 questões específicas, total de 20 questões, porém, na versão digital do questionário (APÊNDICE C) 
em razão da formatação do formulário, algumas questões foram desmembradas resultando em 09 (nove) questões sociodemográficas e 14 questões específicas, totalizando 23 questões.

A pesquisa foi primeiramente apresentada à IES para avaliação e autorização e, com o Termo de Autorização da Instituição - TAI (ANEXO A), o projeto foi submetido ao Comitê de Ética em Pesquisa (CEP) da Universidade de Mogi das Cruzes para apreciação e aprovação. Após a aprovação do CEP, os graduandos de enfermagem foram contatados e informados sobre os objetivos da pesquisa, bem como sobre os seus direitos como participantes, que sua participação seria voluntária não havendo ônus ou bônus, sobre os riscos e benefícios, conforme descritos no TCLE e apresentados a seguir:

Direitos: os participantes tiveram garantido a autonomia, sigilo dos dados coletados, anonimato, direitos de desistência de participar a qualquer momento da pesquisa, bem como, se houvesse qualquer quebra destes direitos, a garantia de indenização e assistência a que legalmente tenham direito.

Riscos: Como o procedimento realizado envolveu o preenchimento de um questionário (impresso ou digital), neste estudo não estão previstos riscos físicos, mas, poderia haver um leve desconforto frente ao processo de preenchimento do questionário, pois, os graduandos de enfermagem poderiam se deparar com questões que podiam lhe parecer delicadas por estar diretamente ligadas ao seu processo de ensino-aprendizagem e, caso ocorresse tal desconforto durante o preenchimento do questionário para minimizar os riscos previstos, no momento do convite, fora ele feito de forma presencial ou remoto, os graduandos foram orientados que, em qualquer momento do preenchimento do questionário se sentissem tal desconforto, não seria obrigado a responder as questões e se tivessem dúvidas durante o preenchimento deveriam comunicar-se com o(s) pesquisador(es) que estará(iam) aplicando o questionário de forma presencial ou no formato remoto por meio do WhatsApp, o(s) qual(is) irá(ão) orientar e melhor conduzir as dúvidas.

Os graduandos de enfermagem também foram orientados a responder cada pergunta no seu tempo e apenas quando se sentissem seguros, não sendo obrigados a responder a todas as perguntas da pesquisa. Se mesmo, com o auxílio, o desconforto persistisse durante o preenchimento do questionário, os pesquisadores iriam interromper o 
procedimento, cancelando a sua participação neste estudo, para que maiores riscos não ocorressem.

Critérios para encerramento e suspensão da pesquisa: Caso não houvesse a ocorrência dos riscos previstos, que estão relacionados à possíveis desconfortos, não haveria previsão para a suspensão da pesquisa, e o encerramento se daria ao término da obtenção dos resultados e sua publicação.

Benefícios: os participantes serão beneficiados diretamente, pois, os resultados poderão contribuir para o seu processo de ensino-aprendizagem, subsidiando-o no desenvolvimento do conhecimento no campo da assistência de enfermagem à neonatos em uso de PICC com foco nas ações de prevenção de ICS, além de contribuir para o fortalecimento do papel do enfermeiro na atuação com neonatos em uso de PICC.

Após aprovação do CEP, os pesquisadores entraram em contato com os graduandos de enfermagem por meio do grupo de WhatsApp dos alunos do Curso de Graduação em Enfermagem, do qual os pesquisadores fazem parte, e fizeram o convite para participação na pesquisa. Caso ainda estivesse na vigência do isolamento social, no momento da coleta de dados, aos graduandos que aceitaram participar da pesquisa, foi solicitado um e-mail para contato e, por meio deste, os pesquisadores formalizaram o convite e enviaram o link para acesso ao TCLE DIGITAL e após o aceite deste, foi enviado para cada participante em modo remoto, o link para preenchimento do questionário digital.

No momento da coleta de dados, as atividades acadêmicas retornaram em modo presencial, e os pesquisadores apresentaram o projeto de pesquisa aos graduandos de enfermagem, entregaram o TCLE impresso e após a assinatura deste, aplicaram o questionário.

Para a fundamentação teórica e ao alcance do objetivo deste estudo, as pesquisadoras realizaram um levantamento bibliográfico nas bases de dados da LILACS (Literatura Latino-Americana e do Caribe em Ciências da Saúde), SciELO (Scientific Electronic Library Online), e BDENF (Banco de Dados em Enfermagem - Bibliografia Brasileira), por meio da BVS (Biblioteca Virtual em Saúde) utilizando os descritores em saúde: assistência de enfermagem, controle de infecção, corrente sanguínea, terapia intensiva neonatal, estratégias, papel do enfermeiro, prevenção, segurança do paciente. 
Os descritores foram utilizados aos pares: Terapia intensiva neonatal and assistência de enfermagem; Terapia intensiva neonatal and controle de infecção; Terapia intensiva neonatal and fatores relacionados ao uso do PICC; Terapia intensiva neonatal and infecção de corrente sanguínea; Terapia intensiva neonatal and papel do enfermeiro; Terapia intensiva neonatal and assistência de enfermagem and prevenção; Terapia intensiva neonatal and controle de infecção and prevenção; Cateter central de inserção periférica and infecção relacionada ao cateter; Medidas Preventivas and infecção de corrente sanguínea; Bloodstream infections and Anvisa, utilizando a sequência das bases de dados, primeiramente na LILACS, SciELO e por último a BDENF.

Os critérios de inclusão para a obtenção dos dados foram: texto completo, no idioma português, com publicação nos últimos ıo anos, com assuntos principais Neonatologia, Enfermagem, Enfermagem Neonatal, Cuidados de Enfermagem, Fatores de Risco

Infecções Relacionadas a Cateter. Como critérios de exclusão: artigos que não atenderam aos critérios de inclusão, os artigos duplicados nas bases de dados e os que não atenderam a temática deste estudo.

Os artigos foram tratados primeiramente com uma leitura flutuante e, os que atenderam às questões norteadoras deste estudo posteriormente foram lidos minuciosamente e agrupados em categorias temáticas para a elaboração do referencial teórico.

Houve a seleção de 38 artigos inicialmente para a leitura, análise e compreensão do tema, tendo como base os títulos e descritores relacionados a: Terapia Intensiva Neonatal e Assistência de Enfermagem, Terapia Intensiva Neonatal e Controle de Infecção, Terapia Intensiva Neonatal e o Papel do Enfermeiro, Terapia Intensiva Neonatal e Prevenção.

A partir da discussão em reunião com a orientadora, as discentes iniciaram o processo de seleção de material a ser referenciado. Foram excluídos 29 artigos que não correspondiam a temática abordada, ou seja, se relacionavam a assuntos menos consonantes com o objetivo definido na pesquisa e, por apresentarem mérito de pesquisa e/ou artigos de revisão da literatura. 
$\mathrm{Na}$ plataforma LILACS ocorreu um primeiro cruzamento com o6 artigos e utilizados 02, no segundo cruzamento or artigo utilizado, no terceiro cruzamento obteve-se o6 artigo e utilizados 02 e no quarto cruzamento o5 artigos e utilizado or.

$\mathrm{Na}$ plataforma da SciELO houve um primeiro cruzamento com ro artigos que foram utilizados e no segundo cruzamento selecionou-se 04 artigos e utilizado apenas or. $\mathrm{Na}$ BDENF houve um cruzamento e utilizado or artigo.

Os dados foram analisados por meio da Análise de Conteúdo de Minayo (200o, p. 203), utilizando-se da Técnica de Análise Temática que relaciona estruturas semânticas com estruturas sociológicas, articula a descrição e análise dos textos com os fatores que determinam suas características, "fazer uma análise temática consiste em descobrir os núcleos de sentido que compõem uma comunicação cuja presença ou frequência signifiquem alguma coisa para o objetivo analítico visado”.

A técnica de Análise Temática, de acordo com Minayo (2000, p.209-210) é realizada a partir de três etapas subsequentes: I $^{\underline{a}}$ Etapa - retomada das hipóteses e objetivos da pesquisa; $2^{\text {a }}$ Etapa - o material será explorado e codificado, classificado, onde serão escolhidas as "categorias teóricas ou empíricas que comandarão a especificação dos temas"; $3^{\text {a }}$ Etapa - o material será submetido à uma análise estatística simples por meio de percentagem e, a partir desta análise serão realizadas as inferências e interpretações. A partir deste roteiro descrito por Minayo (2000), os dados foram codificados.

\section{REFERENCIAL TEÓRICO}

\section{DESCRIÇÃO E INDICAÇÃO DO USO DO PICC EM NEONATOLOGIA}

O PICC é um dispositivo intravenoso, inserido em veias de regiões periféricas e progride por meio de uma agulha introdutora, até a porção final da veia cava, adquirindo características de cateter central (CAMARA, 200I).

Apresenta vários tamanhos de acordo com o calibre das veias do paciente e o tipo de tratamento ao qual será submetido, sendo um cateter longo de 20 a 60 centímetros de comprimento e varia de i a 5 French $(\mathrm{Fr})$ de calibre tendo um ou dois lúmens (CAMARA, 200I).

Os Cateteres são confeccionados de dois tipos de materiais: 
ELASTÔMERO DE SILICONE (SILASTIC), é macio e flexível e requer técnica e procedimento especial de inserção por sua constituição macia e flexível. Possui paredes mais grossas e suportam menos pressões com maiores chances de rompimentos ou perfuração, tromboresistentes e reduzida aderência bacteriana (SOBETI, 2004).

O POLIURETANO é mais rígido que o silicone, facilitando a introdução do cateter em paredes finas e maior tensão de distensão do que cateter de silicone (PHILLIPS, 200I).

O PICC é disponibilizado comercialmente em duas formas de apresentação (CAMARGO, 2007):

- MATERIAL COMPLETO: campos cirúrgicos, torniquetes, fita métrica, soluções antissépticos, agulha introdutória, tesoura, seringas, pinça auxiliar para inserção, gazes, adesivos transparentes e o cateter.

- MATERIAL BÁSICO: fita métrica, agulha introdutória e o cateter.

Segundo os autores Pettit \& Wyckoff (2007), o CCIP é indicado para terapêutica parenteral prolongada e a vantagem de seu uso é ser mais seguro para infusão de soluções vesicantes, causando menor estresse, desconforto, entre outros. $\mathrm{O}$ cateter venoso central (CVC) tuneilizado ou cirurgicamente inserido é associado a maior taxa de infecção comparado ao CCIP.

Os autores Bittencourt, Lamblet \& Silva (2006), relatam que a indicação do uso do PICC é para pacientes que necessitam de acesso venoso prolongado, principalmente se este for submetido a nutrição parenteral total, infusão de drogas vesicantes contínuas, antibioticoterapia, soluções hipertônicas, presença de distúrbios de coagulação e necessidade de medidas de PVC (pressão venosa central). A indicação para inserção do PICC deve ser efetivada pelo médico. Na sequência, o enfermeiro habilitado avalia o paciente quanto à disponibilidade de acesso venoso e condições clínicas.

\section{FATORES RELACIONADOS À ICS ASSOCIADA AO USO DE PICC EM NEONATOS}

A utilização de cateteres centrais para manejo clínico e terapêutico de um paciente faz parte da rotina assistencial de médicos e enfermeiros, o que inclui também a detecção 
de um possível diagnóstico de infecção relacionada ao uso deste cateter, baseando-se nos sinais clínicos e laboratoriais. (MAGALHÃES, 2013).

A infecção primária de corrente sanguínea (IPCS) é descrita como o tipo de infecção que desencadeia alterações sistêmicas importantes, como a bacteremia e sepse, e por não ser possível discernir o foco primário, isso dificulta a associação do cateter central com a ocorrência da condição. Associamos a infecção ao PICC quando o paciente ainda estiver em uso do mesmo na conclusão do diagnóstico, ou após sua retirada no período de até 48 horas. (CATARINO et al., 2013).

Classificamos as IPCS como:

I. Laboratorial: definida por uma ou mais hemoculturas que confirmem a presença de microrganismos da própria pele, mas que não são contaminantes, e que não tenham relação com outro foco infeccioso; surgimento de um sinal ou sintoma que não tenha associação com outras condições do paciente, nem com a infecção de um outro sítio; cultivo de hemocultura de um dos microrganismos contaminantes da pele, que devem ser colhidos de dois locais diferentes e em um intervalo de até 48 horas. Para os pacientes em uso de CVC, cultivo de estafilococo coagulase-negativa em hemocultura periférica. (MACHADO; ANTUNES; SOUZA, 2017; CATARINO et al., 2013).

II. Clínica: o diagnóstico da IPCS clínica terá como critério "pelo menos um sinal e sintoma sem outra causa reconhecida", bem como "hemograma com $\geq 3$ parâmetros alterados e/ou Proteína C Reativa quantitativa alterada; hemocultura não realizada ou negativa; ausência de evidência de infecção em outro sitio e terapia antimicrobiana instituída e mantida pelo médico assistente", dados estes obrigatórios para a confirmação da condição. (MACHADO; ANTUNES; SOUZA, p. 90, 2017).

De acordo com Magalhães (2013, p. II), "os fatores de risco para a infecção devem ser considerados por ocasião da instalação e manutenção do cateter e estão relacionados ao paciente, ao tipo de cateter, ao tipo de solução administrada, ao profissional que manipula o cateter e o agente etiológico". Além disso, a infecção pode ser propiciada pela idade gestacional dos pacientes recém-nascidos, principalmente nos casos dos prematuros, por conta da fragilidade dos sistemas orgânicos e as baixas reservas de nutrientes.

\section{ESTRATÉGIAS E AÇÕES UTILIZADAS POR ENFERMEIROS COMO MEDIDAS PREVENTIVAS PARA A ICS ASSOCIADA AO USO DE PICC EM NEONATOS}

Existem meios para que a infecção de corrente sanguínea associada ao uso do PICC seja combatida, sendo por intervenções durante a sua inserção ou na manipulação diária. A enfermagem é responsável pela capacitação da equipe para com o manuseio e manutenção do cateter, assim como a identificação precoce dos sinais e sintomas advindos da infecção, 
entretanto, mesmo com a capacitação e também a elaboração de protocolos e diretrizes para serem usados como base na prática dos cuidados com o PICC, ainda existe um alto índice de ICS ocorrendo no meio hospitalar. (SILVA, 2017; SILVA et al., 2019; SILVA et.al, 2021).

Pensando nisso, o Institute for Health Improvement (IHI), no ano de 2004, formulou um bundle, ferramenta que se assemelha com protocolos, guidelines e checklists, e que é composta por medidas e cuidados específicos desenvolvidos por uma equipe de especialistas e baseados em evidências científicas, visando a redução das taxas de ICS e eventos adversos, além de proporcionar uma prática de saúde mais segura. (SILVA, 2017; SILVA et al., 2019; SILVA et.al, 2021).

Diante disso, o Centers for Disease Control and Prevention (CDC) também criou um guideline, dessa vez no ano de 20II, com práticas e ações para auxiliar na prevenção de infecções relacionadas ao uso de cateteres. Algumas das principais medidas citadas são:

I. Realizar educação continuada aos profissionais com o intuito de promover informações adequadas sobre o procedimento de inserção e manutenção corretas do cateter, além de medidas de prevenção de infecções.

II.Designar este tipo de procedimento apenas para profissionais treinados e que possuem competência para realizar a inserção e manutenção de cateteres centrais e periféricos.

III.Avaliar o local de inserção do cateter diariamente por palpação através do curativo para identificar sinais de sensibilidade, ou por inspeção caso o curativo seja transparente.

IV.Realizar a higiene das mãos com sabão e água, ou com produtos à base de álcool e que não necessitam de enxague. Deve ser feita antes e depois da palpação do local de inserção, bem como antes e depois de inserir, substituir, manusear, fazer reparos e trocas de curativo em um cateter.

V.Utilizar luvas estéreis para realizar o procedimento de inserção do cateter central no paciente.

VI.Utilizar luvas estéreis ou de procedimento ao trocar curativos.

VII.Utilizar barreiras máximas de precação, como touca, máscara, avental estéril, luvas estéreis e campo estéril durante a inserção do PICC.

VIII.Antes da inserção de um cateter e durante as trocas de curativo, fazer a limpeza da pele do paciente com solução de Clorexidina $0.5 \%$ e álcool.

IX.Utilizar gaze estéril ou curativo estéril transparente e semipermeável para cobrir o local da inserção.

X.Fazer a troca de curativo caso o mesmo esteja úmido, solto ou apresente algum tipo de sujidade.

XI.Fazer a troca de o curativo a cada dois dias para curativos com gaze, ou pelo menos a cada sete dias para curativos transparentes. (CDC, 20Ir; ANVISA, 2013). 


\section{FORMAÇÃO DO ENFERMEIRO GENERALISTA}

O desenvolvimento de atividades e ações com embasamento teórico-científico que visam atenção integral à saúde da população, caracterizam a prática clínica. $O$ enfermeiro atua almejando ações curativas, de promoção, prevenção e recuperação à saúde em diversos cenários de atuação (KAHL; MEIRELLES; CUNHA; BERNARDO; ERDMANN, 20I9).

O papel desempenhado pelos enfermeiros no cumprimento de objetivos de saúde é regulamentado pela Lei n. 7.498, de 25 de junho de 1986 que normatiza o exercício profissional de enfermagem (BRASIL, 1986).

Em 2001, o Ministério da Educação instituiu as Diretrizes Curriculares Nacionais (DCNs), para garantir equivalência à formação de profissionais, considerando o crescente surgimento de Cursos de Graduação em Enfermagem em distintas instituições de ensino superior no Brasil. As DCNs dos Cursos de Graduação em Enfermagem, condicionam a formação de enfermeiros com abrangência nacional, definindo os fundamentos, princípios, procedimentos e aplicabilidades destes na formação profissional (BRASIL, 200I).

As DCNs destacam o perfil do egresso, com formação generalista, por meio de perspectivas humanistas, assistindo à população nos seus diversos níveis de complexibilidade, I4 tendo rigor intelectual e científico, a fim de intervir em situações de saúde-doença inseridos no contexto e dimensões biopsicossociais do ser humano, com liderança, comunicação efetiva e o gerenciamento das ações e dos serviços. (BRASIL, 200I).

O currículo de enfermagem recebeu uma proposta de dinamizar e qualificar o processo de ensino-aprendizagem, que propõe de acordo com o parecer do Conselho Nacional de Educação (CNE/CES) r.133/2001, estabelecidas pela DCNs o abandono de práticas antigas e herméticas que aprisionam o currículo, a fim de garantir a flexibilidade e diversidade, que preparem o enfermeiro egresso para as constantes transformações da sociedade e avanços da profissão e do exercício profissional, que consequentemente resultam em mudanças no mercado de trabalho. Sendo assim, é importante (re)considerar o processo de formação dos futuros enfermeiros que irão se deparar com constantes mudanças no cenário da profissão (BRASIL, 200I). 
O processo de formação qualifica o profissional a desenvolver suas atribuições. Nesse contexto, a gestão do ensino é empreendida pelos docentes, pois os mesmos possuem embasamento teórico, realizam a escolha de metodologias, ferramentas e estratégias a serem utilizadas, definem os espaços necessários para este processo, além do domínio em habilidades técnicas, que os tornam mentores do conhecimento (FREITAS; SANTOS; LIMA; MIRANDA; VASCONCELOS; NAGLIATE, 20I6).

Para isso, a formação do enfermeiro deve ser direcionada aos diversos cenários de trabalho que esses profissionais podem estar desempenhando, que variam entre setores públicos e privados, com desenvolvimento de competências definidas pela resolução $n$. 581/2018 do Conselho Federal de Enfermagem (COFEN) que regulamenta as áreas de atuação por níveis de abrangência:

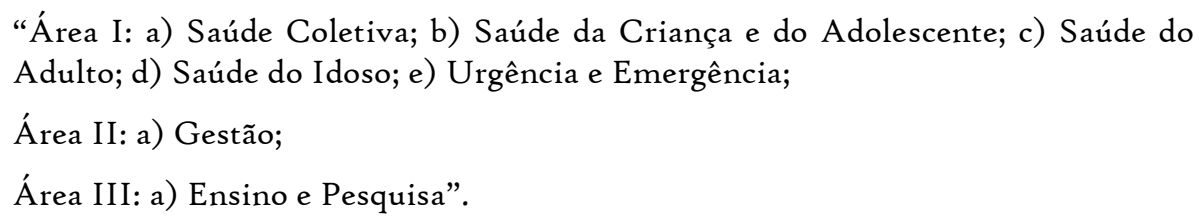

Os campos de conhecimentos da enfermagem na área de pesquisa em Ciências da Saúde são compostos pelas subáreas: Saúde do Adulto e Idoso, Saúde da Mulher, Saúde da Criança e do Adolescente, Saúde Mental, Saúde Coletiva, Enfermagem Fundamental e Enfermagem na Gestão e Gerenciamento.

\section{COMPETÊNCIAS E HABILIDADES DO ENFERMEIRO PARA A ASSISTÊNCIA DE NEONATOS EM USO DE PICC}

$\mathrm{Na}$ prática clínica, o uso do Cateter Central de Inserção Periférica (CCIP) expandiu-se nas últimas décadas, com base no desenvolvimento dos dispositivos vasculares e do conhecimento de suas indicações. Pela Resolução nº 258/200I, o Conselho Federal de Enfermagem dispôs ser de atribuição do enfermeiro a inserção, manutenção e a remoção do CCIP, quando houver indicação de seu uso (COFEN, 200I).

Em se tratando de procedimento de instalação do PICC, nota-se que segundo a lei 7498/86, decreto 94406/87, resoluções do COFEN n 240/200o (Código de Ética dos Profissionais de Enfermagem), COFEN n ${ }^{\circ}$ 258/2001, RDC n ${ }^{\circ} 45$ da Agência Nacional de Vigilância Sanitária (ANVISA), que é de autonomia e competência técnica do enfermeiro a instalação do PICC, desde que este detenha de habilitação teórico prática por meio de 
curso com certificação, porém a manipulação deste é realizada por toda a equipe de enfermagem, este manuseio justifica o processo de educação continuada eficaz para todos os profissionais envolvidos no processo de cuidados (BAGGIO et al., 2ого; MOTTA et al., 20II; TEIXEIRA et al., 20II; VIEIRA et al., 2013).

\section{RESULTADOS E DISCUSSÃO}

\section{DADOS SOCIODEMOGRÁFICOS}

\begin{tabular}{|c|c|c|c|}
\hline & iáveis & Frequência (n) & Porcentagem (\%) \\
\hline \multirow{4}{*}{ Idade } & Até 25 anos & 15 & 68,18 \\
\hline & 25 a 35 anos & 4 & $\mathrm{I} 8, \mathrm{I} 8$ \\
\hline & 35 a 45 anos & 2 & 9,09 \\
\hline & $>45$ anos & $\mathrm{I}$ & 4,55 \\
\hline \multirow{3}{*}{ Sexo } & Total & 22 & 100,00 \\
\hline & Feminino & 18 & 81,82 \\
\hline & Masculino & 4 & $\mathrm{I} 8, \mathrm{I} 8$ \\
\hline \multicolumn{2}{|r|}{ Total } & 22 & IOo,oo \\
\hline
\end{tabular}
entendermos melhor o público participante. Foram convidados 22 graduandos do curso de enfermagem ao todo, sendo 81,82 do sexo feminino, e $18,18 \%$ do sexo masculino, com idade variadas, de até 25 anos (68,18\%), 25 a 35 anos (18,18\%), 35 a 45 anos (9,09\%) e de 45 anos em diante $(4,55 \%)$.

\begin{tabular}{|c|c|c|c|}
\hline Auxiliar ou Técnico em Enfermagem & & Frequência (n) & $\begin{array}{c}\text { Porcentagem } \\
(\%)\end{array}$ \\
\hline \multirow{3}{*}{ Atua na área } & Sim & 6 & 31,58 \\
\hline & Não & 16 & 84,21 \\
\hline & Total & 22 & I00,00 \\
\hline \multirow{6}{*}{ Tempo de atuação } & Dois anos & I & I6,67 \\
\hline & Oito anos & I & I6,67 \\
\hline & Doze anos & 2 & 33,33 \\
\hline & Treze anos & I & I6,67 \\
\hline & $\begin{array}{l}\text { Quinze } \\
\text { anos }\end{array}$ & $\mathrm{I}$ & I6,67 \\
\hline & Total & 6 & I00,00 \\
\hline
\end{tabular}


Apenas 6 graduandos atuam ativamente na área como auxiliar ou técnico de enfermagem, totalizando $31,58 \%$, enquanto os que ainda não exercem a profissão somam 84,21\%. Em relação ao tempo de atuação, as respostas foram variadas, com quatro profissionais que possuem dois, oito, treze e quinze anos de trabalho, representando $16,67 \%$ cada um, e outros dois que atuam há doze anos, totalizando $33,33 \%$.

\begin{tabular}{|c|c|c|c|}
\hline \multicolumn{2}{|l|}{ Graduação em Enfermagem } & $\begin{array}{l}\text { Frequência } \\
\text { (n) }\end{array}$ & $\begin{array}{l}\text { Porcentagem } \\
(\%)\end{array}$ \\
\hline \multirow{3}{*}{ Semestre do Curso de Enfermagem } & $6^{\circ}$ Semestre & 5 & 22,73 \\
\hline & $8^{\circ}$ Semestre & 17 & 77,27 \\
\hline & Total & 22 & 100,00 \\
\hline \multirow{3}{*}{$\begin{array}{l}\text { Cursou ou está cursando a disciplina de Enfermagem em } \\
\text { Neonatologia }\end{array}$} & Sim & 20 & 90,91 \\
\hline & Não & 2 & 9,09 \\
\hline & Total & 22 & 100,00 \\
\hline \multirow{3}{*}{ Está em Regime de Dependência (DP) } & Sim & 22 & 100,00 \\
\hline & Não & o & o,oo \\
\hline & Total & 22 & I00,00 \\
\hline
\end{tabular}

Dos entrevistados, $22,73 \%$ estão no sexto semestre da graduação, e 77,27 estão no oitavo semestre, e enquanto 90,91\% já cursaram ou estão cursando a disciplina de Enfermagem em Neonatologia, somente 9,09 não cursaram. Além disso, nenhum dos participantes está em regime de dependência nesta disciplina.

\begin{tabular}{llc}
\multicolumn{1}{c}{ Especialização } & Frequência (n) & $\begin{array}{c}\text { Porcentagem } \\
\text { (\%) }\end{array}$ \\
\hline Atenção Primária em Saúde (ESF; Saúde Pública) & 7 & 23,33 \\
Obstetrícia e Saúde da Mulher & 5 & 16,67 \\
Urgência e Emergência & 4 & 13,33 \\
Enfermagem em Oncologia & 3 & Io,oo \\
Áreas de gestão (Educação Continuada e Auditoria) & 2 & 6,67 \\
CME e Centro Cirúrgico & 2 & 6,67 \\
Áreas & 2 & 6,67 \\
Enfermagem do Trabalho & I & 3,33 \\
Cardiologia e Hemodinâmica & I & 3,33 \\
Cuidados paliativos & I & 3,33 \\
Enfermagem em Geriatria & I & 3,33 \\
Enfermagem em Nefrologia & I & 3,33 \\
Unidade de Terapia Intensiva & 30 & Ioo,oo \\
\hline Total & & 2 \\
\hline
\end{tabular}


Das possíveis áreas de especialização dos graduandos, 23,33\% gostariam de seguir na Atenção Primária em Saúde (Estratégia Saúde de Família e Saúde Pública), 16,67 em Obstetrícia e Saúde da Mulher, 13,33\% em Urgência e Emergência, e Io\% em Enfermagem em Oncologia. As áreas de gestão (Educação Continuada e Auditoria), Central de Material

e Esterilização e Centro Cirúrgico, e Enfermagem do Trabalho, somam 20,01\%, enquanto Cardiologia e Hemodinâmica, Cuidados Paliativos, Enfermagem em Geriatria, Nefrologia e Unidade de Terapia Intensiva somam 16,65\%.

\section{I) Questões sobre Conhecimento do cateter}

a) O graduando conhece o cateter central de inserção periférica?

\begin{tabular}{ccc}
\hline Unidade de Registro & Frequência (n) & Porcentagem (\%) \\
\hline Sim & 19 & 86,36 \\
Não & 3 & 13,64 \\
\hline TOTAL & 22 & 100
\end{tabular}

b) Características do cateter:

\begin{tabular}{ccc}
\hline Unidade de Registro & $\begin{array}{c}\text { Frequência } \\
\text { (n) }\end{array}$ & $\begin{array}{c}\text { Porcentagem } \\
(\%)\end{array}$ \\
\hline Dispositivo inserido perifericamente em localização central & 7 & 30,4 \\
Tubo de silicone flexível & 5 & $2 \mathrm{I}, 7$ \\
Dispositivo longo & 3 & $13, \mathrm{I}$ \\
Não sabe/não se recorda & 3 & $13, \mathrm{I}$ \\
Mono ou duplo-lúmen & 3 & $13, \mathrm{I}$ \\
Tubo de poliuretano & $\mathrm{I}$ & 4,3 \\
Tamanhos variados & $\mathrm{I}$ & 4,3 \\
\hline TOTAL & 23 & 100 \\
\hline
\end{tabular}

Sobre o conhecimento do cateter pelos graduandos, verificou-se que em relação as características do mesmo, trata-se de um dispositivo inserido perifericamente em localização central (30,4\%), e formado por um tubo de silicone flexível (2I,7\%).

c) Indicação de uso:

\begin{tabular}{ccc}
\hline Unidade de Registro & $\begin{array}{c}\text { Frequência } \\
(\mathrm{n})\end{array}$ & $\begin{array}{c}\text { Porcentagem } \\
(\%)\end{array}$ \\
\hline Infusões de longa permanência & 12 & $4 \mathrm{I}, 3$ \\
Infusão de soluções diversas & 6 & 20,7 \\
Terapia medicamentosa & 3 & 10,4 \\
Uso nutricional & 3 & 10,4 \\
Não sabe/não se recorda & 3 & 10,4 \\
Má condição de acesso venoso & 2 & 6,8 \\
\hline TOTAL & 29 & 100 \\
\hline
\end{tabular}


Quanto à indicação de uso, os participantes mencionaram que o cateter é utilizado em situações em que as infusões são de longa permanência (41,3\%), ou de soluções diversas, como drogas vasoativas, irritantes e antibioticoterapia (20,7\%).

A literatura descreve o PICC como sendo um cateter longo e flexível, variando de 20 a 60 centímetros, com calibre de i a 5 French $(\mathrm{Fr})$, material composto por silicone ou poliuretano, podendo apresentar uma ou duas vias; é inserido em uma veia superficial periférica do corpo, e através de uma agulha introdutória, se estende para a veia cava superior ou inferior, o que lhe confere características semelhantes a um cateter central. (BELO, et al., 2012; DIAS, 2015; SOUZA, et al., 2016).

O dispositivo é indicado nos casos em que o paciente necessita de acesso venoso por período prolongado (maior que seis dias), e administração de soluções irritantes, hipertônicas e vesicantes, terapia medicamentosa e nutrição parenteral total. (FERREIRA, et al., 2020; MITTANG, et al, 2020; KEGLER, et al., 2016).

As respostas obtidas para estes dois primeiros tópicos da pesquisa convergem com as informações retiradas da literatura, demonstrando que os graduandos realmente conhecem o cateter, como responderam no primeiro quadro, bem como sua indicação. Além disso, eles também citaram que o cateter poderia ser de mono ou duplo-lúmen ( $13,1 \%)$, de tubo de poliuretano com tamanhos variados, somando $8,6 \%$, como os autores acima descrevem. As terapias medicamentosas (I0,4\%) e nutricionais (10,4\%) também foram mencionadas, e vão de encontro com a fala dos autores.

\section{2) Condições de preparo para inserção do PICC:}

Acerca das condições de preparo para a inserção do PICC, dividiu-se o tema em três pontos principais:

a) Condição do enfermeiro, cujas respostas abordam os recursos utilizados pelos profissionais da enfermagem para realização do procedimento, sendo elas: curso de capacitação para inserção do PICC (19,05\%), higiene do ambiente e das mãos (I6,6\%) e utilização de técnica asséptica/estéril (II,9\%). 


\begin{tabular}{ccc}
\hline Unidade de Registro & $\begin{array}{c}\text { Frequência } \\
\text { (n) }\end{array}$ & $\begin{array}{c}\text { Porcentagem } \\
(\%)\end{array}$ \\
\hline Curso de capacitação para inserção de PICC & 8 & 19,05 \\
Higiene do ambiente e das mãos & 7 & $\mathrm{I} 6,6$ \\
Utilização de técnica asséptica/estéril & 5 & $\mathrm{II}, 9$ \\
Não sabe/não se recorda & 4 & 9,52 \\
Habilidade para realizar o procedimento & 4 & 9,52 \\
Providenciar os materiais necessários e utilizar EPIs & 4 & 9,52 \\
Avaliar condições do RN & 3 & 7,14 \\
Conhecimento técnico-científico & 3 & 7,14 \\
Presença de outro profissional no procedimento & $\mathrm{I}$ & 2,4 \\
Verificar da área de punção & $\mathrm{I}$ & 2,4 \\
Verificar identificação do paciente & $\mathrm{I}$ & 2,4 \\
Orientação aos pais sobre o procedimento & $\mathrm{I}$ & 2,4 \\
\hline TOTAL & 42 & $\mathrm{IOO}$ \\
\hline
\end{tabular}

b) Condição do recém-nascido, considerando sua condição geral clínica e de agravo $(22,8 \%)$, avaliação da rede venosa (17,1\%) e posicionamento adequado do RN $(14,3 \%)$.

\begin{tabular}{ccc}
\hline Unidade de Registro & $\begin{array}{c}\text { Frequência } \\
\text { (n) }\end{array}$ & $\begin{array}{c}\text { Porcentagem } \\
(\%)\end{array}$ \\
\hline Condição geral clínica e de agravo do neonato & 8 & 22,8 \\
Avaliação da rede venosa & 6 & $17, \mathrm{I}$ \\
Posicionamento adequado do RN & 5 & 14,3 \\
Não sabe/não se recorda & 5 & 14,3 \\
Uso de técnica asséptica & 3 & 8,57 \\
Antissepsia e condição da pele & 3 & 8,57 \\
Escolhe adequada do cateter e seu calibre & 2 & 5,71 \\
Higienização das mãos & 2 & 5,71 \\
Autorização dos pais/responsáveis & $\mathrm{I}$ & 2,85 \\
\hline TOTAL & 35 & Ioo
\end{tabular}

c) Preparo da pele do recém-nascido, sendo necessária a realização da antissepsia do local da punção $(39,3 \%)$, utilização de clorexidina - degermante ou alcóolica (I4,3\%) e uso de álcool 70\% (Io,7\%).

\begin{tabular}{ccc}
\hline Unidade de registro & $\begin{array}{c}\text { Frequência } \\
\text { (n) }\end{array}$ & $\begin{array}{c}\text { Porcentagem } \\
\text { (\%) }\end{array}$ \\
\hline Realizar antissepsia do local da punção & $\mathrm{II}$ & 39,3 \\
Uso de clorexidina & 4 & 14,3 \\
Uso de álcool 70\% & 3 & 10,7 \\
Procedimento estéril & 3 & 10,7 \\
Não sabe/não se recorda & 3 & 10,7 \\
Avaliação da pele e rede venosa & 3 & o,7 \\
Higienização das mãos & $\mathrm{I}$ & 3,6 \\
\hline TOTAL & 28 & I00
\end{tabular}


De acordo com Bomfim et.al (2019, p. 177), “o enfermeiro é reconhecido como profissional habilitado para a inserção do CCIP, desde que seja submetido à qualificação e/ou capacitação profissional", tendo assim o conhecimento integral no que diz respeito à indicação, inserção e manutenção do dispositivo. O procedimento também exige materiais específicos e a monitorização do paciente. (MITTANG, et al., 2020).

Apesar das respostas dos graduandos se aproximarem com a dos autores, levando em consideração que indicaram também a providência dos materiais necessários (9,52\%), foi possível perceber que a literatura é extremamente limitada quando se trata da relação entre os enfermeiros e suas funções para manter o procedimento seguro. A capacitação profissional é indispensável, entretanto, é importante salientar outros pontos apontados pelos participantes, como a utilização dos equipamentos de proteção individual (EPIs), higiene das mãos, utilização de técnica asséptica/estéril, verificação da identificação do $\mathrm{RN}$, bem como de suas condições gerais e da área a ser puncionada, além da prestação de orientação clara e íntegra do procedimento aos pais e responsáveis.

Como ciência do cuidado, a enfermagem é incumbida de se atentar a estes detalhes e promover uma assistência segura e eficaz ao paciente, como forma de o proteger, e também proteger a equipe. $O$ não seguimento de algum desses aspectos pode tornar o procedimento ineficaz e causar riscos desnecessários aos recém-nascido, além de infringir o Código de Ética dos Profissionais de Enfermagem.

Das condições do recém-nascido, não foi encontrado na literatura descrições suficientes sobre o tema, portanto somente as respostas coletadas durante a pesquisa serão consideradas. O ponto mais citado foi a condição geral clínica e de agravo do neonato, e a partir disto surgiu também o questionamento de alguns graduandos sobre a real necessidade do uso do cateter.

Em sequência, foi indicada a avaliação da rede venosa, e de acordo com Bomfim, Passos e Silva (2017, p 134), "a veia cefálica e basílica são as mais utilizadas, sendo a basílica, a mais recomendada em razão de seu maior calibre, menor número de válvulas e a de mais fácil manipulação no procedimento de troca de curativo”. Recomenda-se também evitar o acesso femoral, pelo risco elevado de formação trombótica e maior chances de ocorrência de infecção sanguínea relacionada ao uso do cateter. (DUARTE, et al., 2013). 
Os graduandos também apontaram sobre o posicionamento adequado do RN, que segundo Belo et al. (2012), ocorre da seguinte maneira: "a posição do RN deve ser decúbito dorsal, mantendo preferencialmente, o membro superior direito em ângulo de $90^{\circ}$ em relação ao tórax, mensurar com fita métrica o local de inserção do cateter até a altura da clavícula, e desse ponto até o $3^{\mathrm{o}}$ espaço intercostal direito onde a ponta do cateter deve ter sua visualização radiográfica no terço distal da veia cava superior".

Além disso, foi possível identificar que 14,3\% dos participantes não sabiam ou não se recordavam sobre quais aspectos do recém-nascido deveriam ser levados em conta para a utilização do cateter, o que é justificado pela ausência de discussão do tópico nos artigos científicos nacionais, e a falta de informação fundamentada sobre o assunto.

Para o preparo referente a pele do neonato, é necessário considerar seu peso. Recémnascidos que apresentam peso abaixo de 1.500 gramas possuem uma maior fragilidade da pele, o que demanda o uso de clorexidina degermante, e para os que apresentam peso acima de 1.500 gramas, a recomendação é do uso se clorexidina alcóolica. A Infusion Nurse Society (INS) aconselha ainda o emprego da clorexidina alcóolica $>0,5 \%$, entretanto, se houver alguma objeção, o álcool $70 \%$ pode ser usado em substituição, sendo que o profissional deve deixar a solução secar completamente antes de realizar a inserção do cateter ou fazer a troca de curativo. (PEREIRA, et al., 202I).

Novamente, percebemos que os graduandos compreendem inteiramente mais um tópico da pesquisa, mas um graduando em particular citou, diferentemente da literatura, um detalhe importante do processo, a higienização das mãos. Há cinco momentos que devem ser respeitados com relação a ela: antes de entrar em contato com o paciente, antes da realização de um procedimento asséptico, após ao risco de exposição a algum fluido corporal, após o contato direto com o paciente e com áreas próximas a ele. Seguindo estes passos, garantimos a total segurança de nosso paciente e promovemos barreiras contra microrganismos. 


\section{3) Conhecimento sobre o processo de inserção do cateter com segurança no paciente:}

\begin{tabular}{ccc}
\hline Unidade de Registro & $\begin{array}{c}\text { Frequência } \\
(\mathrm{n})\end{array}$ & $\begin{array}{c}\text { Porcentagem } \\
(\%)\end{array}$ \\
\hline Uso de técnica asséptica/estéril & $\mathrm{II}$ & 33,3 \\
Não sabe/não se recorda & 5 & $15, \mathbf{r}$ \\
Antissepsia da pele & 3 & 9,09 \\
Posicionamento correto do RN & 3 & 9,09 \\
Uso de EPIs & 2 & 6,06 \\
Dupla checagem da medicação & 3 & 6,06 \\
A mbiente asséptico & 2 & 6,06 \\
Planejamento e controle de inserção & 2 & 6,06 \\
Monitorização cardiorrespiratória & $\mathrm{I}$ & 3,03 \\
Higiene das mãos & $\mathrm{I}$ & 3,03 \\
Explicar o procedimento aos pais/responsáveis & $\mathrm{I}$ & 3,03 \\
\hline TOTAL & 33 & 100
\end{tabular}

Em relação ao conhecimento dos graduandos sobre o processo de inserção do cateter com segurança no paciente, obteve-se que 33,3\% reconhecem que o procedimento exige a utilização de técnica asséptica/estéril, e $15,1 \%$ não sabiam ou não se recordavam da resposta.

Conforme Bomfim, Passos e Silva (2017, p. 184), "a inserção do cateter ocorre na seguinte ordem: identificação da veia apropriada, posicionamento do paciente; verificação da medida do comprimento do cateter; paramentação; abertura completa do material e colocação de campo estéril sob o local de punção escolhido; antissepsia; lubrificação do cateter com solução salina; preparação do comprimento do mesmo; aplicação do torniquete e preparo do conjunto introdutor; execução de venopunção; retirada da agulha da bainha introdutória; inserção do cateter periférico. Teste de permeabilidade do cateter; retirada do campo fenestrado; limpeza do local de inserção; fixação do cateter, fechamento do sistema; confirmação radiológica da posição da ponta do cateter.”

No procedimento de inserção também deve constar a técnica de barreira máxima contra infecções e outros cuidados fundamentais como a monitorização cardiorrespiratória, sedação e analgesia para manejo da dor. (BELO, et al., 2012).

Neste questionamento da pesquisa, os graduandos, apesar de não apresentarem como nos outros momentos respostas satisfatórias em maior frequência, é possível destacar algumas particularidades próprias da inserção e que foram lembradas por eles, como o posicionamento adequado do RN (9,09\%), uso de EPIs (9,09\%) e monitorização cardiorrespiratória (3,03\%). Outro fator significativo é o esclarecimento acerca do procedimento para os pais ou responsáveis pela enfermagem, visto que eles serão 
incumbidos a autorizar a equipe a realizar a inserção do cateter e necessitarão de informações suficientes para compreensão da terapêutica adotada.

\section{4) Conhecimento em relação a manutenção da permeabilidade do cateter:}

\section{a) Cuidados de enfermagem:}

\begin{tabular}{ccc}
\hline Unidade de registro & $\begin{array}{c}\text { Frequência } \\
(\mathbf{n})\end{array}$ & $\begin{array}{c}\text { Porcentagem } \\
(\%)\end{array}$ \\
\hline Cuidados específicos relacionados ao curativo & 20 & $4 \mathrm{I}, 6$ \\
Higienizar local com soluções & $\mathrm{I} 2$ & 25 \\
Aferir sinais vitais & 6 & $\mathrm{I2,5}$ \\
Não sabe/não se recorda & 3 & 6,25 \\
Antissepsia do conector com swab de álcool & 2 & 4,16 \\
Utilizar técnica asséptica & 2 & 4,16 \\
Manter acesso salinizado/aqualizado & 2 & 4,16 \\
Heparinização & $\mathrm{I}$ & 2,08 \\
\hline TOTAL & 48 & I00
\end{tabular}

Acerca dos conhecimentos em relação a manutenção da permeabilidade do cateter, abrangendo os cuidados de enfermagem, os graduandos referem os cuidados específicos relacionados ao curativo, como: a verificação das condições gerais do curativo e acesso (sinais flogisticos, obstrução, vazamento, secreções e sangue), manter o curativo sempre limpo e seco, e que ele seja feito somente por enfermeiros; realizar o primeiro curativo após $48 \mathrm{~h}$ pós punção, e protege-lo com plástico filme durante o banho; e prestar orientação aos pais e responsáveis sobre os cuidados com o curativo (4I,6\%); higiene do local com soluções como soro fisiológico $0,9 \%$ ou $0,5 \%$ e álcool 70\%, antes e depois da administração de medicação e nutrição (25\%); e aferição dos sinais vitais (I2,5\%), indicando que a pressão arterial deve ser aferida no braço que não estiver recebendo o acesso.

A realização do curativo é crucial para promover a manutenção assertiva do PICC, já que é uma forma de proteção e prevenção de possíveis traumas locais e de contaminação. Uma infinidade de materiais pode ser utilizada para esta prática, e por exigir técnica estéril, a troca deve ser feita por profissionais capacitados, visando manter as barreiras contra a infecção associada ao cateter, e o conhecimento de qual cobertura é mais eficaz para cada caso corrobora para a preservação do acesso venoso. (PEREIRA, et al., 202I).

Pereira et.al (2020, p. I9I) também aponta que "quando inserido, o PICC deve ser fixado com gaze e fita adesiva estéril devido a presença de sangramento ou diaforese, sendo realizado a troca a cada 48 horas ou cobertura estéril transparente que deve ser trocada a cada sete dias, ambos devem ser trocados imediatamente se presença de sujidade, 
umidade ou descolamento, sempre com o objetivo de redução de infecção por corrente sanguínea (IPCS)”. Este fato demanda do enfermeiro e realização de avaliação diária tanto da cobertura, como do acesso em si, mantendo a integridade do curativo e seguindo as medidas de prevenção contra infecções. (PEREIRA, et al., 202I).

A técnica do flushing (lavagem do lúmen de um cateter), de acordo com Pereira et. al (202I, p. 19I)" deve ocorrer em intervalo de 6 horas, com infusão de solução fisiológica a o,9\%, utilizando volume de 0,5 a I,o $\mathrm{ml}$ e seringa de io $\mathrm{ml}$ ou maior volume”, sempre antes e após uma infusão, mantendo assim o controle de avalição do dispositivo e dificultando a associação de medicações incompatíveis entre si. (DIAS, 2015).

Comprova-se, mais uma vez, que os graduandos dominam o conhecimento referente à manutenção da permeabilidade do cateter, e mesmo que de forma breve, eles também mencionam a utilização de técnicas assépticas (4,16\%), o acesso salinizado/aqualizado (4,16\%), e o emprego da heparinização (2,08\%).

5) Conhecimento sobre os fatores relacionados a ICS associados ao uso de PICC:

a) Sinais de infecção:

\begin{tabular}{ccc}
\hline Unidade de Registro & $\begin{array}{c}\text { Frequência } \\
\text { (n) }\end{array}$ & $\begin{array}{c}\text { Porcentagem } \\
(\%)\end{array}$ \\
\hline Rubor & I6 & $27, \mathrm{II}$ \\
Dor & 8 & 13,55 \\
Secreção purulenta & 7 & $\mathrm{II}, 9$ \\
Calor & 6 & $\mathrm{Io,16}$ \\
Hiperemia & 6 & $\mathrm{IO}, \mathrm{I} 6$ \\
Edema & 5 & 8,47 \\
Febre & 3 & 5,08 \\
Sensibilidade local & 2 & 3,38 \\
Sinais flogísticos & 2 & 3,38 \\
Hipertermia & $\mathrm{I}$ & $\mathrm{I}, 7$ \\
Sujidade sanguinolenta & $\mathrm{I}$ & $\mathrm{I}, 7$ \\
Infiltração & $\mathrm{I}$ & $\mathrm{I}, 7$ \\
Não sabe/não se recorda & $\mathrm{I}$ & $\mathrm{I}, 7$ \\
\hline TOTAL & 59 & 99,99 \\
\hline
\end{tabular}

Os dados coletados e seus respectivos resultados demonstram um conhecimento satisfatório dos graduandos sobre os sinais indicativos de infecção que podem ocorrer devido ao uso do dispositivo PICC, estando de acordo com o que discorre a literatura.

Analisando os dados, o maior sinal de infecção apontado pelos graduandos foi o rubor com 27,11\%, seguido de dor com 13,55\%, secreção purulenta com II,9\%, calor com ıо,16\%, hiperemia com 10,16\%, edema com $8,47 \%$ e febre com $5,08 \%$. A sensibilidade local e 
sinais flogísticos (sem especificação) somam 3,38\% do que aponta os entrevistados, já a presença de hipertermia, sujidade sanguinolenta, infiltração e aqueles que não sabem ou não se recordam totalizaram $1,7 \%$.

O autor Motta et al. (2011), diz que a infecção é constatada através dos seguintes sinais de hiperemia e de edema local, presença de secreção purulenta, febre, leucocitose e culturas positivas. A infecção pode ser causada devido à técnica inadequada, colonização do cateter, infecções prévias e condições dos pacientes. Após a detecção destes sinais é importante que o cateter seja retirado e encaminhado para a realização de exame de cultura. A antibioticoterapia está indicada nestes casos, lembrando que o tratamento será de acordo com o agente etiológico.

A avaliação eficaz dos sinais vitais e do local de inserção do PICC possibilitam a deteç̧ão de qualquer alteração do quadro clínico do RN, correspondem à verificação da temperatura, frequência respiratória (FR), pressão arterial (PA), frequência cardíaca $(\mathrm{FC})$ e principalmente a verificação precoce dos sinais flogísticos que possam aparecer no local de inserção do PICC ou remoção indevida, portanto, cabe a toda equipe de enfermagem a observação desses aspectos. $\mathrm{Na}$ unidade de alto risco, a verificação dos sinais vitais deve ser realizada a cada $4 \mathrm{~h}$, a PA a cada $6 \mathrm{~h}$ ou de acordo com a necessidade do $\mathrm{RN}$ e o curativo do PICC avaliado constantemente ou a cada introdução de fluidos e troca de curativo, de forma cuidadosa e criteriosa (MOREIRA, et al., 2004).

Caso houver intercorrências como temperatura acima de $37,5^{\circ} \mathrm{C}$, PA inferior ou superior $80 / 50 \mathrm{mmHg}$, e FC inferior a Ioobpm e superior a I6obpm, FR inferior a 40irpm e superior a 6oirpm, o técnico de enfermagem ou enfermeiro deve discutir o caso com o neonatologista ou enfermeiro habilitado em neonatologia; quanto ao curativo, se este estiver úmido, sujo ou solto e/ou pele com sinais flogísticos o enfermeiro neonatologista deve agir rapidamente afim evitar danos irreversíveis (OLIVEIRA, 2005).

Os dados vitais devem ser checados mesmo nos RNs monitorizados, e de preferência sincronizados com outros procedimentos necessários, evitando o manuseio excessivo do bebê. Adotar a política do mínimo toque traz conforto para o bebê, melhorando seu padrão de sono e seu prognóstico (MOREIRA, et al., 2004) 


\section{b) Principais fatores:}

\begin{tabular}{ccc}
\hline Unidade de Registro & $\begin{array}{c}\text { Frequência } \\
\text { (n) }\end{array}$ & $\begin{array}{c}\text { Porcentagem } \\
\text { (\%) }\end{array}$ \\
\hline Manutenção e manuseio incorretos do cateter & $\mathrm{I} 2$ & 29,26 \\
Higiene inadequada das mãos & 7 & 17,07 \\
Não utilização de técnica asséptica/estéril & 7 & 17,07 \\
Tempo de uso do cateter & 3 & 7,31 \\
Preparo inadequado da pele & 3 & 7,31 \\
Falta de troca de curativos & 3 & 7,31 \\
Não sabe/não se recorda & 2 & 4,9 \\
Contaminação por bactérias e infecc̃ão cruzada & 2 & 4,9 \\
Falta de conhecimento técnico-científico & $\mathrm{I}$ & 2,43 \\
Local de inserção & & 2,43 \\
\hline TOTAL & $\mathrm{I}$ & 99,99 \\
\hline
\end{tabular}

Como principais fatores relacionados a ICS e associados ao uso de PICC, os graduandos apontaram que o de maior relevância é em relação a manutenção e manuseio incorretos do cateter por parte de toda equipe médica e de enfermagem totalizando $29,26 \%$, seguido da higienização inadequada das mãos e não utilização de técnicas assépticas e estéreis durante a manipulação e cuidados com 17,07\%. Em sequência e em mesma frequência se encontram como fatores o tempo de uso do cateter, a falta de troca de curativos e preparo inadequado da pele do RN com 7,31\%.

Apenas 4,9\% dos entrevistados apontou como fator relacionados a ICS a contaminação por bactérias e infecção cruzada. Uma mesma parcela não se recorda ou não sabe quais os possíveis fatores. Em conseguinte, 2,43\% apontaram a falta de conhecimento científico e aspectos relativos ao local de inserção como fatores predisponentes de ICS.

Quanto a verificação das complicações relacionadas à infecção é de grande responsabilidade do enfermeiro, pois a monitorização dos sinais como hipertermia, rubor e secreção no óstio da inserção devem ser realizados diariamente. Evidenciando repetidamente a importância de profissionais treinados e familiarizados com a técnica do PICC para que possam intervir nas complicações precocemente. As principais complicações relacionadas à pós-inserção do cateter são: flebite, celulite, infecção sistêmica, oclusão e migração do cateter e potencial risco de embolia e trombose (MONTES, TEIXEIRA, BARBOSA, BARICHELLO, 2OII).

De modo geral, os estudos apontaram que o PICC, quando comparado a outros Cateteres Venoso Central (CVC), apresenta menor incidência de complicações, o que 
fortalece a tese de que é um dispositivo seguro e muito útil em especialidades como terapia intensiva, oncologia e neonatologia, em que o acesso venoso dos pacientes é extremamente limitado e difícil. Porém, a despeito da baixa frequência desse evento indesejável, sua ocorrência produz impactos extremamente relevantes do ponto de vista econômico e clínico, comprometendo principalmente a segurança do paciente. (BRETAS, et al., 2013).

Os cuidados referentes à manutenção são direcionados, principalmente, no controle da infecção hospitalar, destacando-se pela adoção de técnicas assépticas para manuseio do dispositivo, realização do curativo e higienização adequada das mãos. Somado a estes cuidados, as literaturas sugerem o flushing pulsátil com solução salina a $0,9 \%$, periodicamente. As dificuldades mais comumente encontradas para a manutenção do CCIP em neonatologia foram a presença de infecção, flebite bacteriana, obstrução do cateter por coágulos ou medicamentos, ruptura ou perda acidental do cateter e extravasamento da infusão. (LUI AML, ZILLY A, FRANÇA AFO, et al., 2018)

Enquanto ocorrer a instalação e manutenção do PICC, as práticas de enfermagem adquirem importância como estratégia de segurança ao paciente por influenciarem diante de complicações e consequente remoção não eletiva. Os serviços de saúde têm se organizado e vêm criando grupos de estudos voltados a discutir, propor e aprimorar os protocolos de procedimentos invasivos, incluindo o uso de dispositivos intravasculares. A padronização dos procedimentos de enfermagem, as estratégias de discussão, treinamento e a implementação de rotinas para utilização do PICC são fatores contribuintes para a redução de complicações relacionadas ao uso do cateter (MENEZES, 2005).

6) Percepções dos graduandos quanto ao processo de prevenção e controle da ICS associada ao uso de PICC:

a) Desafios/dificuldades:

\begin{tabular}{ccc} 
Unidade de Registro & $\begin{array}{c}\text { Frequência } \\
\text { (n) }\end{array}$ & $\begin{array}{c}\text { Porcentagem } \\
(\%)\end{array}$ \\
\hline Falta de especialização e conhecimento técnico-científico & 7 & 24,13 \\
Manutenção e manipulação inadequadas do dispositivo & 5 & 17,24 \\
Déficit de Educação Continuada & 4 & 13,8 \\
Não Sabe/Não Se Recorda & 4 & 13,8 \\
Sobrecarga de serviço & 3 & 10,34 \\
Tempo de uso do cateter & 2 & 6,9 \\
Imaturidade do sistema imune & 2 & 6,9 \\
Permanência hospitalar & $\mathrm{I}$ & 3,44 \\
Falta de fiscalização do serviço de enfermagem & $\mathrm{I}$ & 3,44 \\
\hline TOTAL & & \\
\hline
\end{tabular}


Neste quadro, temos a percepção dos graduandos sobre a prevenção de ICS associada ao uso de PICC, onde foram questionados sobre quais seriam os desafios e dificuldades enfrentados pelo enfermeiro.

Como principal fatores indicaram a falta de especialização e conhecimento técnicocientífico totalizando 24,13\%. Com $17,24 \%$, indicaram a manutenção e manipulação inadequadas do dispositivo. Em conseguinte, citaram possível déficit de educação continuada, mas em mesma proporção se encaixaram aqueles que não sabem/não se recordam com $13,8 \%$.

Um fator importante apontado foi a sobrecarga de serviços do enfermeiro com Iо,34\%. O tempo de uso e imaturidade do sistema imune somaram 6,9\% das respostas dos entrevistados. Uma pequena parcela de $3,44 \%$ citou a permanência hospitalar prolongada e falta de fiscalização do serviço de enfermagem como sendo uma dificuldade.

Os autores citam que dentre os avanços tecnológicos observados no campo da saúde está o PICC, exigindo dos enfermeiros conhecimentos técnicos científicos em relação à sua manipulação e manutenção, a fim de evitar complicações e proporcionar uma assistência de qualidade, providências que contribuem para o tratamento adequado a diminuição do tempo de internação (GOMES, NASCIMENTO, ANTUNES, ARAUJO, 2010).

A “[...] falta de qualidade de formação ensino-serviço, teórico-prática de muitos programas no cenário nacional”, segundo Sassi e Machado (2017, p. 790), expõe o profissional a diversos estressores. Portanto, é necessário um preparo psicológico e compreensão dos serviços para a adaptação do novo profissional que irá se submeter a um campo de atuação, muitas vezes, sem conhecimento específico necessário para uma qualidade assistencial na área quem é inserido (SASSI; MACHADO, 2017).

As literaturas analisadas no decorrer da pesquisa, reforçam a utilização de evidências científicas fortes na prática profissional e dos instrumentos básicos para o desenvolvimento dos cuidados de enfermagem, visando ao reconhecimento e a autonomia do profissional com consequente melhoria da qualidade do serviço prestado. (RODRIGUES; CHAVES; CARDOSO, 2006). 
Estudos demonstram que conhecer o perfil do RN submetido ao PICC é essencial para prever situações de risco e afirmar a indicação e tempo de uso de forma mais eficaz (ROSA, et al., 2014).

Para reduzir as ocorrências que comprometem a permanência do cateter é requerida a capacitação e a educação permanente dos profissionais, no sentido de desenvolver conhecimento, destreza e habilidade para o manuseio do PICC. Isso evidencia que os entrevistados reconhecem a importância destes requisitos para uma atuação satisfatória do enfermeiro em neonatologia.

Não foram encontrados dados na literatura referentes a fiscalização do serviço de enfermagem relacionado aos cuidados com o PICC em unidades de terapia intensiva neonatal.

b) Estratégias para prevenção da ICS:

\begin{tabular}{ccc}
\hline Unidade de Registro & $\begin{array}{c}\text { Frequência } \\
\text { (n) }\end{array}$ & $\begin{array}{c}\text { Porcentagem } \\
(\%)\end{array}$ \\
\hline Orientação e treinamento da equipe de enfermagem & 12 & 28,57 \\
Uso de técnica asséptica & 6 & 14,28 \\
Higienização das Mãos & 5 & 11,90 \\
Manuseio e manutenção do dispositivo & 4 & 9,52 \\
Monitoração do paciente & 3 & 7,14 \\
Higienização do dispositivo & 3 & 7,14 \\
Não Sabe/Não Se Recorda & 3 & 7,14 \\
Utilização de Pops & 2 & 4,76 \\
Troca de curativo & 2 & 4,76 \\
Orientação pais/responsáveis sobre estratégias de prevenção & 2 & 4,76 \\
\hline TOTAL & 42 & 99,97 \\
\hline
\end{tabular}

Neste quadro, temos a percepção dos graduandos sobre a prevenção de ICS associada ao uso de PICC, onde foram questionados sobre quais seriam as estratégias de prevenção utilizadas pelo enfermeiro.

Com mais de $28 \%$ os alunos apontaram a orientação e treinamento da equipe de enfermagem como sendo a estratégia principal de prevenção a ICS. O uso de técnica asséptica foi apontado por $14,28 \%$ dos entrevistados, seguido da higienização das mãos com II,90\%. Em conseguinte foi apontado o manuseio e manutenção do dispositivo com 9,52\%. A monitoração do paciente, higienização do dispositivo e os que não sabem/não se 
recordam somam cada um 7,14\%. Se encaixam a utilização de POPs, a troca de curativo e orientação dos pais/responsáveis cada um com taxa de 4,76\% dos entrevistados.

Estudos evidenciam a troca do curativo do PICC a cada sete dias no caso de película transparente ou na presença de sujidade, umidade, sangramento ou bordas com pouca adesão cutânea (PINTO et al., 2017). A utilização da película transparente semipermeável oferece a visualização do sítio de inserção, atua como barreira para microrganismos externos (SIRQUEIRA \& SOUZA, 2017), aumenta o tempo de permanência do cateter, proporciona conforto ao paciente e menor custo à instituição (CAVALCANTE, 2015).

Considerando que a inserção do cateter é o momento crítico para a ocorrência de infecção, o monitoramento sobre a inserção é uma forma de manter essas taxas constantemente baixas (ROSADO et al., 2018).

Quanto aos cuidados durante a cateterização, estão consolidadas as recomendações de antissepsia das mãos, uso de barreira máxima estéril, antissepsia da pele com clorexidina $0,5 \%$ e secagem completa do produto, utilização de kits de inserção prémontados, equipe exclusiva com treinamento especializado em inserção e manutenção de cateter venosos central (CURAN \& ROSSETTO, 2017).

Atualmente, qualquer debate sobre as infecções de corrente sanguínea prevê a discussão acerca dos indicadores de processo, os quais estão intrinsicamente envolvidos com as práticas diárias executadas pelos profissionais de saúde (BRASIL, 2017). As mãos constituem a principal via de transmissão de microrganismos durante a assistência prestada aos pacientes (BRASIL, 2017).

Por isso, higienizá-las é o caminho mais efetivo para prevenir infecções (HAMMOUD et al., 2017).

Legeay et al. (2015) alertaram que a transmissão de microrganismos patogênicos pelas mãos dos profissionais pode levar à circulação de cepas endêmicas por longos períodos. No que tange à antissepsia das conexões por io segundos e a troca do oclusor ao abrir o sistema, estudiosos afirmam que esses cuidados resultam em diminuição significativa de infecção associada ao cateter (BOMFIM, PASSOS \& SILVA, 20I7; PINTO et al,. 2017), auxiliando na prevenção de colonização extraluminal (SILVA et al., 2019), recomendações também pontuadas pela ANVISA (BRASIL, 2019). 
A verdadeira prevenção da infecção precisa da aderência restrita aos bundles e protocolos institucionais (LEGEAY, 2015).

Não foram encontrados na literatura consultada dados referentes a orientação dos pais/responsáveis sobre estratégias de prevenção, o que evidencia a necessidade de mais pesquisas sobre o tema.

7) Importância da SAE e instrumentos metodológicos utilizados para prevenção de ICS associada ao uso de PICC:

a) SAE:

\begin{tabular}{ccc}
\hline Unidade de Registro & $\begin{array}{c}\text { Frequência } \\
\text { (n) }\end{array}$ & $\begin{array}{c}\text { Porcentagem } \\
\text { (\%) }\end{array}$ \\
Cuidados assertivos & 5 & 17,24 \\
Não sabe/não se recorda & 5 & 17,24 \\
Prescrição de enfermagem & 4 & 13,79 \\
Utilização do processo de enfermagem & 3 & 10,34 \\
Pops & 2 & 6,90 \\
Planejamento das ações de enfermagem & 2 & 6,90 \\
Avaliação contínua do paciente & 2 & 6,90 \\
Melhor qualidade assistencial & 2 & 6,90 \\
Baixo risco de infecção & 2 & 6,90 \\
Organização e orientação da equipe & $\mathrm{I}$ & 3,44 \\
Gestão do tempo & $\mathrm{I}$ & 3,44 \\
TOTAL & 29 & 99,99
\end{tabular}

Relacionado ao uso da SAE e instrumentos metodológicos utilizados para prevenção de ICS associada ao uso de PICC, os graduandos citaram os cuidados assertivos como sendo o principal meio para prevenção de agravos ao RN somando $17,24 \%$. Em mesma porcentagem se encaixam os entrevistados que não sabem ou não se recordam de instrumentos ou da função da SAE neste processo.

Com 13,79\% citam o uso da prescrição de enfermagem e $10,34 \%$ a utilização do processo de enfermagem. Como ferramentas para prevenção citaram o uso de POPS, o planejamento das ações de enfermagem, avaliação contínua do paciente e uso de ferramentas de qualidade da assistência, totalizando $6,90 \%$. A organização e orientação da equipe e gestão do tempo somaram $3,44 \%$ das respostas dos entrevistados.

Um dado importante é sobre a alta taxa de entrevistados que referiram não saber ou não se recordar da SAE ou de instrumentos que possam subsidiar o enfermeiro na assistência aos recém-nascidos em uso de PICC, evidenciando uma possível lacuna de aprendizado. 
A resolução COFEN 358/o9 estabelece a Sistematização da Assistência de Enfermagem (SAE), atividade privativa do enfermeiro, busca a identificação das situações saúde/doença dos indivíduos por meio da utilização de um método científico que irá subsidiar ações de enfermagem contribuindo para a promoção, prevenção, recuperação e reabilitação da saúde dos indivíduos.

Ela é simplesmente a forma como o enfermeiro vem buscando agregar cientificidade para organizar as ações de prestação do cuidado. A utilização da SAE possibilita ao enfermeiro realizar com maior eficácia ações de supervisão, de avaliação e de gerenciamento dos cuidados prestados, bem como acompanhar os resultados das ações implementadas. O Processo de Enfermagem (PE) deve estar baseado em um suporte teórico que oriente a coleta de dados, o estabelecimento de diagnósticos de enfermagem e o planejamento das ações ou intervenções de enfermagem (COSTA, PAES, 2012).

b) Instrumentos metodológicos (escalas preditivas, indicadores, instrumento de monitoramento do PICC, protocolos):

\begin{tabular}{ccc}
\hline Unidade de Registro & $\begin{array}{c}\text { Frequência } \\
\text { (n) }\end{array}$ & $\begin{array}{c}\text { Porcentagem } \\
\text { (\%) }\end{array}$ \\
\hline POP - Procedimento Operacional Padrão & 7 & 26,92 \\
Não sabe/não se recorda & 6 & 23,07 \\
Escala de Madox & 5 & 19,23 \\
Classificação de edema & 2 & 7,69 \\
Classificação de febre & $\mathrm{I}$ & 3,84 \\
Protocolo de higienização das mãos & $\mathrm{I}$ & 3,84 \\
Protocolo de sepse & $\mathrm{I}$ & 3,84 \\
Escala Likert - avaliação de sítio de inserção & $\mathrm{I}$ & 3,84 \\
Escala DINI - Dimensionamento do Cuidado & $\mathrm{I}$ & 3,84 \\
Checklist de passagem de PICC & $\mathrm{I}$ & 3,84 \\
\hline TOTAL & 26 & 99,95 \\
\hline
\end{tabular}

No quadro os graduandos apontaram com instrumentos metodológicos o uso de procedimentos operacionais padrão com 26,92\%. Em taxa alta de 23,02\% estavam os entrevistados que não sabem ou não se recordam do assunto. Em conseguinte, apresentaram a escala de Madox com 19,23\%. Em seguida consideraram escala de classificação de edema totalizando 7,69\% dos entrevistados. Com 3,84\% cada, responderam como instrumentos metodológicos escala de classificação de febre, protocolo de higienização das mãos e de sepse, escala Likert para avaliação de sítio de inserção, escala DINI (Dimensionamento do Cuidado) e adoção de checklist de passagem de PICC. 
A literatura consultada aborda o uso de protocolos assistenciais próprios e individuais a cada instituição para regulamentar as responsabilidades da equipe multiprofissional e as condutas de implantação, manutenção e remoção do PICC para garantir a segurança dos pacientes neonatais e pediátricos. Assim como a adoção de procedimentos operacionais padrão para inserção de PICC, retirada, manutenção de curativos e técnica de desobstrução.

O sucesso para inserção do CCIP aumenta mediante o conhecimento sobre suas propriedades, bem como, com a capacitação do profissional responsável pela inserção e manutenção do dispositivo e da equipe que atua continuamente com o cateter. Nesse sentido, é fundamental avaliar as práticas que envolvem a inserção e o manejo desse procedimento, a qualificação profissional e a necessidade de protocolos para prevenir complicações e garantir qualidade na assistência. Tais precauções tornam-se importantes para reduzir a morbimortalidade neonatal por complicações relacionadas ao uso de dispositivos intravenosos $(7,8)$.

Estudos demonstram que o protocolo de instalação do PICC deve conter informações acerca das características do cateter escolhido (diâmetro e volume interno do cateter), do sítio de inserção, das intercorrências durante o procedimento e do laudo radiográfico. Além disso, informações relacionadas à manutenção (troca de curativo, avaliação das condições locais e permeabilidade do cateter, bem como a remoção e causa da retirada, comprimento do cateter retirado e envio da ponta para análise microbiológica) devem ser registradas através de instrumentos impressos ou eletrônicos, o que auxilia a assistência de enfermagem a padronizar o cuidado, qualificando a assistência prestada (DANSKI et al., 2016; SWERTS et al., 2013).

8) Competências e habilidades do enfermeiro na assistência à saúde de recém-nascidos em uso de PICC:

\begin{tabular}{|c|c|c|}
\hline Unidade de Registro & $\begin{array}{l}\text { Frequência } \\
\text { (n) }\end{array}$ & $\begin{array}{c}\text { Porcentagem } \\
(\%)\end{array}$ \\
\hline Curso de capacitação de PICC & 9 & 24,32 \\
\hline Conhecimento técnico-científico & 8 & 21,62 \\
\hline Habilidade prática & 5 & $13,5 \mathrm{I}$ \\
\hline Não sabe/não se recorda & 5 & 13,51 \\
\hline $\begin{array}{l}\text { Princípios (ética, responsabilidade, } \\
\text { organização, liderança, humanização) }\end{array}$ & 5 & 13,51 \\
\hline Raciocínio clínico e crítico & 2 & 5,40 \\
\hline Eficiência na tomada de decisão & 2 & 5,40 \\
\hline Orientação dos pais/responsáveis & I & 2,70 \\
\hline TOTAL & 37 & 99,97 \\
\hline
\end{tabular}


O conhecimento dos graduandos quanto as habilidades necessárias ao enfermeiro na assistência aos recém-nascidos em uso de PICC demonstra concordância com a literatura, visto que, essa demonstra a necessidade de capacitação específica para sua inserção e manutenção. Porém, há ainda uma parcela do estudo que não se recorda ou não possui conhecimento sobre tais práticas necessárias ao enfermeiro totalizando 13,51\%, mostrando novamente que pode haver uma lacuna de aprendizado que não foi sanada na graduação.

O curso de capacitação foi o mais referido pelos entrevistados com 24,32\%, em seguida abordaram que o conhecimento técnico-científico é importante habilidade do enfermeiro com 21,62\%. A habilidade prática e os princípios - ética, responsabilidade, organização, liderança, humanização também foram citadas pelos graduandos, somando 13,51\%.

O raciocínio clínico e crítico, bem como a eficiência na tomada de decisões somaram 5,40\%. Uma pequena parcela de $2,70 \%$ apontou a orientação dos pais e responsáveis como habilidade necessária ao enfermeiro durante a assistência de recémnascidos, o que demonstra que há a preocupação de alunos em relação a manutenção do vínculo participativo entre paciente-família, mas que ainda não se torna um número representativo.

No que tange a capacitação, a certificação do enfermeiro por grupos reconhecidos pelo COFEN, pode assegurar aspectos teóricos, fundamentais para executar uma boa prática ministrada. Todavia, estar apto a reconhecer os riscos e as complicações decorrentes do dispositivo, bem como tratá-las, depende de cada profissional, o qual deve buscar informações atualizadas sobre o assunto em fontes idôneas. Além disso, há que se ressaltar a necessidade de treinar toda a equipe de enfermagem para o manuseio do dispositivo, tendo-se em vista que a prática da terapia intravenosa, no Brasil, é realizada por todos os profissionais da equipe (BRETAS, et al., 2013).

Salientamos que, os alunos entrevistados demonstraram concordância com que diz a literatura sobre a importância da capacitação para passagem e manutenção do PICC, não estando restrito somente ao enfermeiro, mas também a toda equipe de enfermagem que está envolvida diretamente no cuidado. 
É importante ressaltar que, segundo a resolução COFEN, de I2 de julho de 200I, a passagem do PICC é de responsabilidade do enfermeiro após qualificação e/ou capacitação profissional (CONSELHO FEDERAL DE ENFERMAGEM, 20oI).

A indicação para inserção do PICC deve ser efetivada pelo médico. Na sequência, o enfermeiro habilitado avalia o paciente quanto à disponibilidade de acesso venoso e condições clínicas (BITTENCOURT; LAMBLET; SILVA, 2006). Um cuidado importante a ser considerado é que a indicação seja feita antes que a rede venosa esteja prejudicada por múltiplas punções.

De acordo com a Intravenous Nurses Society (INS) - Brasil, cabe privativamente aos enfermeiros e médicos a realização de tal procedimento, desde que tenham feito a capacitação através de curso e treinamento que inclua os conteúdos teórico-práticos relativos à inserção, manutenção e retirada do cateter, indicações e contra indicações da utilização do dispositivo e métodos de verificação da inserção, a fim de garantir a qualidade do procedimento e o bem-estar do paciente. No Brasil, a atribuição de competência técnica e legal para o enfermeiro inserir e manipular o PICC encontra-se amparada pela Resolução Conselho Federal de Enfermagem (COFEN) no 258/200I (KISHI, CARRARA; CONSELHO FEDERAL DE ENFERMAGEM, 2006, 200I)

A manutenção do PICC, depende necessariamente da capacitação e educação permanente e empenho da equipe de enfermagem. Reconhecer a importância da análise e do cuidado diário do curativo é extremamente relevante para o sucesso na manutenção do PICC.

\section{CONCLUSÃO}

Os dados coletados e seus respectivos resultados demonstram um conhecimento satisfatório dos graduandos sobre as questões aplicadas, mostrando que o objetivo deste estudo foi alcançado. Quando questionados sobre os sinais indicativos de infecção que podem ocorrer devido ao uso do dispositivo PICC, mostraram estar de acordo com o que discorre a literatura.

A literatura consultada evidencia que o cuidado prioritário para inserir e manter o CCIP em recém nascidos e que ampara todo o procedimento refere-se à capacitação profissional e educação permanente da equipe de enfermagem integrante da UTIN, fato 
que fora abordado e levantado como principal fator de dificuldade em relação a manutenção do cateter.

Em relação a orientação dos pais ou responsáveis, mesmo diante de escassez de dados é de suma importância que esta seja realizada quanto ao procedimento a ser realizado, além de se obter o consentimento como forma de respaldo legal para o profissional enfermeiro.

Dentre as dificuldades mais prevalentes para a manutenção do CCIP foram relatados pelos graduandos a presença de infecção, flebite bacteriana, e falta de especialização e conhecimento técnico-científico para manipulação do cateter, estando em consonância com o material científico consultado. A literatura ainda aborda a obstrução do cateter por coágulos ou medicamentos, ruptura ou perda acidental e extravasamento de infusões.

Desta forma, para o manejo adequado do CCIP em ambientes de alto risco, torna-se necessário o constante incentivo à qualificação profissional para que a atenção ao recémnascido grave seja efetiva, contínua e proativa, amparados em bases científicas.

Os cuidados referentes à manutenção do CCIP são direcionados, principalmente, visando o controle de infecção hospitalar, destacando-se pela adoção de técnicas assépticas para manuseio do dispositivo, realização do curativo e higienização adequada das mãos, somado a vários outros cuidados periódicos.

A utilização do PICC requer conhecimento, destreza e habilidade, priorizando o cuidado com a manutenção do cateter. Além disso, o enfermeiro deve conhecer os riscos aos quais os recém-nascidos submetidos a tal procedimento estão expostos, a fim de utilizarem medidas de prevenção, controle e detecção das possíveis complicações.

Assim, podemos afirmar que, a partir dos resultados alcançados o enfermeiro desempenha um papel fundamental, junto à equipe assistencial, pois compete a ele a atualização periódica, os conhecimentos a respeito das diretrizes e competência para inserir e manipular cateteres, tendo em ênfase os cuidados com a manutenção do PICC, delegando cuidados a profissionais competentes para tal função, ressaltando seu papel de educador, padronizando protocolos e disseminando saberes. 
Em suma, deve estar capacitado a exercer atividades de maior complexidade, respaldado em conhecimentos científicos que serão concretizados a partir da prática clínica, a fim de conduzir um atendimento com autoconfiança e segurança a essa clientela.

Uma limitação deste estudo foi a escassez de pesquisas realizadas com graduandos do curso de enfermagem em relação ao uso de CCIP em recém-nascidos, visto que em sua maioria as pesquisas relatadas são realizadas com profissionais já graduados, mostrando uma realidade e perspectiva distinta.

Diante disso, sugerimos a realização e aplicação de estudos acerca do conhecimento de alunos em relação ao uso deste cateter nessa clientela específica, para que se possa obter parâmetros em relação ao ensino-aprendizagem dos graduandos, evidenciando se este é satisfatório ou se existem possíveis lacunas de conhecimento durante a graduação.

\section{REFERÊNCIAS BIBLIOGRÁFICAS}

ANVISA. Agência Nacional de Vigilância Sanitária. Gerência Geral de Tecnologia em Serviços de Saúde. Gerência de Vigilância e Monitoramento em Serviços de Saúde. Critérios Diagnósticos de Infecções Relacionadas à Assistência à Saúde - Neonatologia. Brasília, 2013. Disponível em: https://bvsms.saude.gov.br/bvs/publicacoes/criterios_diagnosticos_infeccoes_assistencia_ saude_neonatologia.pdf >. Acesso em: 23 jul. 202I.

BELO, Marcela Patricia Macêdo; et al. Conhecimento de enfermeiros de Neonatologia acerca do Cateter Venoso Central de Inserção Periférica. Revista Brasileira de Enfermagem, Brasília,v. 65, n. I, p. 42-8, jan-fev; 2012. Disponível em < http://www.scielo.br/pdf/rlae/vi8n2/pt_o8.pdf> Acesso em I8 out. 202I.

BITTENCOURT, A.; LAMBlet, L. C. R.; SILVA, L. M. G. Terapia intensiva enfermagem. Rio de Janeiro: Atheneu, 2006.

BOMFIM JMS, PASSOS LS, SILVA JC. Cateter central de inserção periférica: desafios e estratégias de enfermagem na manutenção do dispositivo. Rev CuidArt. [Internet]. 2017 [acesso em I5 out 202I]; II(I). Disponível em: http://www.webfipa.net/facfipa/ner/sumarios/cuidarte/2017vi/I8\%2oArtigo\%2oCateter_

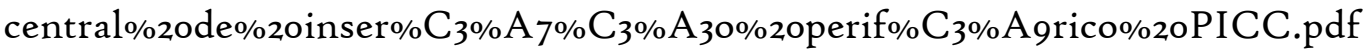


BOMFIM, Joane Margareth Souza et al. Desafios na manutenção do Cateter Central de Inserção Periférica em neonatos. CuidArte, Enferm, p. 174-179, 2019.

BORGHESAN, Nataly Barbosa Alves et al. Cateter venoso central de inserção periférica: práticas da equipe de enfermagem na atenção intensiva neonatal [Peripherally inserted central catheter: practics of nursing team in the neonatal intensive care] [Catéter central de inserción periférica: práctica del equipo de enfermería en la atención intensiva neonatal]. Revista Enfermagem UERJ, [S.1.], v. 25, p. e28143, dez. 2017. ISSN oio4-3552. Disponível em: <https://www.epublicacoes.uerj.br/index.php/enfermagemuerj/article/view/28143>. Acesso em: 27 maio 2021. doi:https://doi.org/10.12957/reuerj.2017.28143.

BRASIL. Agência Nacional de Vigilância Sanitária [homepage na internet]. Medidas de Prevenção de Infecção Relacionada à Assistência à Saúde/Agência Nacional de Vigilância Sanitária [acesso em Io set 2021].

BRASIL. Agência Nacional de Vigilância Sanitária, Prevenção de infecções relacionadas à assistência à saúde em neonatologia. Brasília: Anvisa, 2017b. [acesso em I2 out 202I].

BRASIL. Agência Nacional de Vigilância Sanitária. Critérios Diagnósticos de Infecção Associada à Assistência à Saúde - Neonatologia. Brasília: Anvisa, 2017a. [acesso em ro out 2021].

BRASIL. Lei no 7498 , de 25 de junho de 1986. Dispõe Sobre A Regulamentação do Exercício da Enfermagem e Dá Outras Providências. Brasília.

BRASIL. Ministério da Saúde. Conselho Nacional de Saúde. Resolução CNS no 466 de I2 de dezembro de 2012 que aprova as diretrizes e normas regulamentadoras de pesquisas envolvendo seres humanos. Disponível em: https://bvsms.saude.gov.br/bvs/saudelegis/cns/2013/res0466_I2_I2_2012.html.

BRASIL. Parecer CNE/CES no II33, de 3 de outubro de 200I. Dispõe Diretrizes Curriculares Nacionais do Curso de Graduação em Enfermagem, Medicina e Nutrição. Conselho Nacional de Educação e Câmara de Educação Superior. Brasília (DF), 200 .

BRASIL. Resolução CNE/CES no 3, de 7 de novembro de 200I. Institui Diretrizes Curriculares Nacionais do Curso de Graduação em Enfermagem. Conselho Nacional de Educação e Câmara de Educação Superior. Diário Oficial da União, Brasília (DF), o7 nov. 2001 . 
BRETAS S, et al. Conhecimento da equipe de enfermagem sobre inserção e manutenção do cateter central de inserção periférica em recém nascidos. Enferm. Glob.2013;1I-20.

CATARINO, Camilla Ferreira et al. Perfil epidemiológico das infecções primárias de corrente sanguínea em uma unidade de terapia intensiva neonatal. Revista de Pesquisa Cuidado é Fundamental Online, v. 5, n. I, p. 3229-3237, 2013.

CAVALCANTE RC, MARQUES ADB, BRANCO JGO, COUTO CS, CAMPOS ACS, ROLIM KMC. Cuidados de enfermagem na manutenção do cateter central de inserção periférica em neonatos: revisão integrativa. Rev Pre Infec e Sal. [Internet]. 2015 [acesso em 12 out 202I]; I(2). Disponível em: https://revistas.ufpi.br/index.php/nupcis/article/view/359I/pdf

CENTERS FOR DISEASE CONTROL AND PREVENTION. Guidelines for the Prevention of Intravascular Catheter-Related Infections. 20II. Disponível em:< http://www.cdc.gov/hicpac/pdf/guidelines/bsi-guidelines-20II.pdf >. Acesso em: 23 jul. 2021.

COFEN. Resolução no 58I, de II de julho de 20I8. Atualiza, no âmbito do Sistema Cofen/conselhos Regionais de Enfermagem, Os Procedimentos Para Registro de Títulos de Pós - Graduação Lato e Stricto Sensu Concedido A Enfermeiros e Aprova A Lista das Especialidades. Brasília, DF.

Conselho Federal de Enfermagem (COFEN). Resolução COFEN- 258/20or Inserção de Cateter Periférico Central pelos Enfermeiros. [Legislação na Internet]. São Paulo; 200I[citado em 2I jul. 202I]. Disponível em: http://site.portalcofen.gov.br/node/4296.

Conselho Federal de Enfermagem [homepage na internet]. Resolução no 258 de 12 de julho de 200I. Inserção de Cateter Periférico Central, pelos Enfermeiros. [acesso em is de out. 2021]. Disponível em: http://www.portalcofen.gov.br/legislação/r258.html.

COSTA LC, PAES GO. Aplicabilidade Dos Diagnósticos De Enfermagem Como Subsídios Para Indicação Do Cateter Central De Inserção Periférica. Esc Anna Nery (impr.)2012; 16 (4):649-656.

COSTA, Priscila et al. Fatores de risco para infecção de corrente sanguínea associada ao cateter central de inserção periférica em neonatos. Acta paul. enferm., São Paulo, v. 29, n. 2, p. I6I-I68, Apr. 2016. Available from 〈http://www.scielo.br/scielo.php?script=sci_arttext\&pid=Soro3- 
2100201600020016I\&lng $=$ en $\& \mathrm{nrm}=$ iso $>$.

access

on

o6 Apr. 2021. https://doi.org/10.1590/1982-0194201600023.

CURAN GRF, ROSSETTO EG. Medidas para redução de infecção associada a cateter central em recém-nascidos: revisão integrativa. Texto Contexto - Enferm. [Internet]. 2017 [acesso em o6 out 202I]; 26(I):I-9. Disponível em: http://dx.doi.org/I0.1590/oro407072017005130015.

DANSKI MTR, MINGORANCE P, JOHANN DA, VAYEGO SA, LIND J. Incidência de complicações locais fatores de risco associados ao cateter intravenoso periférico em neonatos. Rev Esc Enferm [Internet]. 2016 [citado em 20 set. 2021]; 50(I):22-8. Disponível em: http://www. scielo.br/pdf/reeusp/v5onI/pt_oo8o-6234-reeusp-50-oI-oo22.pdf.

DIAS, CS. Práticas de Manutenção do Cateter Central de Inserção Periférica em Unidades Neonatais e Pediátricas. Rio de Janeiro, 2015. Dissertação de Mestrado (Mestrado em Enfermagem) - Escola de Enfermagem Anna Nery, Universidade Federal do Rio de Janeiro, Rio de Janeiro, 2015.

Duarte, Elysângela Dittz et al. Fatores associados à infecção pelo uso do cateter central de inserção periférica em Unidade de Terapia Intensiva Neonatal. Revista da Escola de Enfermagem da USP [online]. 2013, v. 47, n. 3 [Acessado 19 Outubro 2021] , pp. 547-554. Disponível em: 〈https://doi.org/ 10.1590/Soo80-623420130000300004〉. ISSN 1980-220x. https://doi.org/ 10.1590/Soo8o-623420130000300004 .

FERREIRA, C. P.; QUERIDO, D. L.; CHRISTOFFEL, M. M.; ALMEIDA, V. S. de; ANDRADE, M.; LEITE, H. C. A utilização de cateteres venosos centrais de inserção periférica na Unidade Intensiva Neonatal. Revista Eletrônica de Enfermagem, Goiânia, Goiás, Brasil, v. 22, 2020. DOI: I0.5216/ree.v22.56923. Disponível em: https://revistas.ufg.br/fen/article/view/56923. Acesso em: I8 out. 2021.

FONTELLES, Marilda Garcia Simões; FARIAS, Samantha Hasegawa; FONTELLES, Renata Garcia Simões. Metodologia da Pesquisa Científica: diretrizes para a elaboração de um protocolo de pesquisa. Rev. Para. Med. (impr,), v. 23, n. 3, jul.-set. 2009. Disponível em: $<$ http://bases.bireme.br/cgi-

$\mathrm{bin} / \mathrm{w} x$ islind.exe/iah/online/?IsisScript $=\mathrm{iah} / \mathrm{iah} . \mathrm{x}$ is \& src $=$ google \&base $=$ LILACS\&lang $=\mathrm{p}$ \&nextAction=lnk\&exprSearch=588477\&indexSearch=ID>. 
FREITAS, Daniel Antunes; SANTOS, Emanuele Mariano de Souza; LIMA, Lucy Vieira da Silva; MIRANDA, Lays Nogueira; VASCONCELOS, Eveline Lucena; NAGLIATE, Patricia de Carvalho. Saberes docentes sobre processo ensino-aprendizagem e sua importância para a formação profissional em saúde. Interface (Botucatu). n.57, v.20, p.43748, 2016.

HAMMOUD MS, AL-TAIAR A, AL-ABDI SY, BOZAID H, KHAN A. ALMUHAIRI LM, et al. Late-onset neonatal sepsis in Arab states in the Gulf region: two-year prospective study. Int J Infect Dis. [Internet]. 2017 [acesso em o8 out 202I]; 55:125-30. Disponível em: http://dx.doi.org/ro.ror6/j.ijid.2017.or.oo6

KAHL, Carolina; MEIRELLES, Betina Horner Schlindwein; CUNHA, Kamylla Santos da; BERNARDO, Mariana da Silva; ERDMANN, Alacoque Lorenzini. Contributions of the nurse's clinical practice to Primary Care. Revista Brasileira de Enfermagem, Florianópolis, v. 72, n. 2, p. 354-359, abr. 2019. FapUNIFESP (SciELO). http://dx.doi.org/10.1590/o034-7167-2018-0348.

KEGLER, Jaquiele Jaciara et al . Manejo da dor na utilização do cateter central de inserção periférica em neonatos. Esc. Anna Nery, , v. 20, n. 4, e20160099, 2016 . Disponível em 〈http://www.revenf.bvs.br/scielo.php?script=sci_arttext\&pid=SI4I4-

81452016000400216\&lng=pt\&nrm=iso $>$. acessos em i9 out. 2021. Epub 20-Out2016. http://dx.doi.org/10.5935/1414-8145.20160099.

LEGEAY C, BOURIGAULT C, LEPELLETIER D, ZAHAR JR. Prevention of healthcare-associated infections in neonates: room for improvement. J Hosp Infect. [Internet]. 2015 [acesso em Io out 2021]; 89(4):319-23. Disponível em: http://dx.doi.org/ro.1016/j.jhin.2015.02.003.

LUI, Andressa Marcelly Lourenço; ZILLY, Adriana; FRANÇA, Andrea Ferreira Ouchi; TONINATO, Ana Paula Contiero; SILVA, Rosane Meire Munhak da. Cuidados e Limitações no Manejo do Cateter Central de Inserção Periférica em Neonatalogia. Revista de Enfermagem do Centro-Oeste Mineiro 2018;8:e1918. DOI: 10.19175/recom.v7io.1918. Dusponível em <www.ufsj.edu.br/recom>.

MACHADO, Camila Duarte; ANTUNES, Fernando Steffen; SOUZA, Patrícia Alves de. INCIDÊNCIA DE INFECÇÕES PRIMÁRIAS NA CORRENTE SANGUÍNEA EM UMA UTI NEONATAL. Arquivos Catarinenses de Medicina, [S.1.], v. 46, n. 2, p. 
88-96, jul. 2017. ISSN I8064280. Disponível em: $\langle$ http://acm.org.br/acm/seer/index.php/arquivos/article/view/272/158〉. Acesso em: 22 jul. 2021.

MAGALHÃES, Talita Elci de Castro. Incidência e fatores de risco de remoção por suspeita de infecção de corrente sanguínea associada ao cateter central de inserção periférica em uma coorte de neonatos. 2013. Dissertação (Mestrado em Cuidado em Saúde) - Escola de Enfermagem, Universidade de São Paulo, São Paulo, 2013. doi:10.11606/D.7.2013.tde-25092013-082540. Acesso em: 2021-07-20.

MENEZES SO. Avaliação do acesso vascular em neonatos com menos de 1500 g internados em Unidades Neonatais da SMS do Rio de Janeiro. [Dissertação]. Instituto Fernandes Figueira, Fundação Oswaldo Cruz. Rio de Janeiro; 2005.

MINAYO, Maria Cecílica de Souza. O desafio do conhecimento: pesquisa qualitativa em saúde. 7. ed., São Paulo: Hucitec; Rio de Janeiro: Abrasco, 2000.

MITTANG, Bruno Tiago et al . CATETER CENTRAL DE INSERÇÃO PERIFÉRICA EM RECÉM-NASCIDOS: FATORES DE RETIRADA. Rev. baiana enferm., Salvador , v. $34, \quad$ e38387, $2020 \quad$. $\quad$ Disponível em $\langle$ http://www.revenf.bvs.br/scielo.php?script=sci_arttext\&pid=S2178-

$86502020000100359 \& \operatorname{lng}=$ pt\&nrm=iso $>$ acessos em 18 out. 2021. Epub 20-Nov2020. http://dx.doi.org/Io.1847I/rbe.v34.38387.

MONTES SF, TEIXEIRA JBA, BARBOSA MH, BARICHELLO E. Ocorrência de complicações relacionadas ao uso de Cateter Venoso Central de Inserção Periférica (PICC) em recém-nascido. Enferm Glob. 2011;10-18.

MOREIRA $\mathrm{M}$ et al. O recém-nascido de alto risco: teoria e prática do cuidar. Fundação Oswaldo Cruz. Rio de Janeiro. 2004; 564.

MOTTA, Neves das Patrícia, et al., Cateter central de inserção periférica: o papel da enfermagem na sua utilização em neonatologia, HU revista Juiz de Fora, v.37, n.2, p. ı63168, abr./jun. 20II, acesso em 28 de dezembro de 2014 ee disponível em: hurevista.ufjf.emnuvens.com.br/hurevista/article/download/1402/546.

Oliveira RG. Blackbook pediatria: medicamentos e rotinas médicas. 3.ed. Belo Horizonte: Black Book. 2005; 629. 
PEREIRA, Higor Pacheco et al. Cateter central de inserção periférica: práticas de enfermeiros na atenção intensiva neonatal. Enfermagem em Foco, [S.1.], v. II, n. 4, jan. 2021. ISSN 2357-707X. Disponível em: 〈http://revista.cofen.gov.br/index.php/enfermagem/article/view/3193/970〉. Acesso em: I9 out. 2021. doi:https://doi.org/10.21675/2357-707X.2020.vir.n3.3193.

PETTIT J, WYCKOFF MM. Peripherally inserted central catheters: guideline for practice. 2nd ed. Glenview: National Association of Neonatal Nurses, [diretriz na internet]. 2007 [Acesso em I8 jul. 2021]. Disponível em: http://www.nann.org/ pdf/PICCGuidelines.pdf.

PINTO MMM, NASCIMENTO VD, VASCONCELOS SP, FREIRE GMM, PENA SBS, SANTOS SDL, POMPEU MRM, RAMOS IO, ROLIM KMC, MAGALHÃES FJ. O enfermeiro no cuidar ao neonato em uso de PICC: revisão integrativa. Rev Tenden. Da Enferm. Profis. [Internet]. 2017 [acesso em is out 2021]; 9(3). Disponível em: http://www.coren-ce.org.br/wp-content/uploads/2019/o2/O-ENFERMEIRO-NOCUIDAR-AO--NEONATO-EM-USO-DE-PICC.pdf.

RANGEL, Regiane Josy Mediote et al. Cateter central de inserção periférica em neonato: revisão integrativa da literatura Central catheter of peripherally insertion in neonates: integrative literature review. Revista de Pesquisa: Cuidado é Fundamental Online, [S.1.], v. 8, n. 4, p. 5193-5202, oct. 2016. ISSN 2175-5361. Disponível em: 〈http://www.seer.unirio.br/index.php/cuidadofundamental/article/view/3751 $>$. Acesso em: o6 apr. 2021. doi:http://dx.doi.org/10.9789/2175-5361.2016.v8i4.5193-5202.

RANGEL, Regiane Josy Mediote et al. Practice of Insertion, Maintenance and Removal of Peripheral Inserted Central Catheter in Neonates / Práticas de Inserção, Manutenção e Remoção do Cateter Central de Inserção Periférica em Neonatos. Revista de Pesquisa: Cuidado é Fundamental Online, [S.1.], v. II, n. 2, p. 278-284, jan. 2019. ISSN 2175-536r. Disponível em: 〈http://www.seer.unirio.br/index.php/cuidadofundamental/article/view/6425〉. Acesso 
em: o6 apr. 2021. doi:http://dx.doi.org/10.9789/2175-5361.2019.viri2.278-284.

ROSADO V, CAMARGOS PAM, ANCHIETA LM, BOUZADA MCF, OLIVEIRA GM, CLEMENTE WT, et al. Fatores de risco para infecção associada a cateteres venosos centrais em população neonatal - revisão sistemática. J Pediatr (Rio J). [Internet]. 2018 [acesso em 12 out 202I]; 94(I):3-I4. Disponível em: http://dx.doi.org/ı.1016/j.jped.2017.03.012

SASSI, Marcelo Machado; MACHADO, Rosani Ramos. Residência Multiprofissional em Urgência e Emergência: A visão do profissional de saúde Residente. Revista de Enfermagem Ufpe OnLine, Recife, v. II, n. 2, p.785-79I, fev. 2017.

Silva MMM, Oliveira-Figueirêdo DST, Cavalcanti AC, Nascimento LC. Infecções de corrente sanguínea relacionada a cateteres centrais: entendimento e prática da equipe de enfermagem. 2021 jan/dez; 13:640-645. DOI: http://dx.doi.org/o.9789/21755361.rpcfo.vi3.9376.

SILVA MPC, BRAGATO AGC, FERREIRA DO, ZAGO LB, TOFFANO SEM, NICOLUSSI AC, CONTIM D, AMARAL JB. Bundle para manuseio do cateter central de inserção periférica em neonatos. Rev Acta Paul Enferm. [Internet]. 2019 [acesso em I5 out 202I]; 32(3). Disponível em: http://dx.doi.org/10.1590/1982-0194201900036

SILVA, AG. Competência da equipe multiprofissional às medidas para prevenção das infecções da corrente sanguínea relacionada ao cateter venoso central, 2017. Dissertação (Mestrado em Enfermagem) - Escola de Enfermagem, Universidade Federal de Minas Gerais, Belo Horizonte, 2017.

SILVA, Maria Paula Custódio et al. Bundle para manuseio do cateter central de inserção periférica em neonatos. Acta Paulista de Enfermagem, v. 32, p. 261-266, 2019.

SIRQUEIRA LC, SOUZA KF. Cuidados de enfermagem na manutenção do cateter central de inserção periférica no recém-nascido. Rev UVRV. [Internet]. 2017 [acesso em Io out 202I]; I5(I). Disponível em: http://dx.doi.org/I0.5892/ruvrd.vi5ir.402I

SOUZA, Renata Rangel Birindiba de et al. O conhecimento do enfermeiro sobre cateter central de inserção periférica: estudo descritivo. Online braz. j. nurs.(Online), p. 21-3I, 2016. SR, KISHI HM, CARRARA D. Inserção e manutenção do PICC: aspectos da prática clínica de enfermagem em oncologia. Prática Hospitalar (São Paulo) 2006;7(47):155-62. 
SWERTS CAS, FELIPE AOB, ROCHA KM, ANDRADE CUB. Cuidados de enfermagem frente às complicações do cateter central de inserção periférica em neonatos. Rev Eletr Enferm [Internet]. 2013 [citado em 20 set. 2021]; 151:156-62. Disponível em: https://www.fen.ufg.br/fen_revista/vi5/ni/pdf/visniai8.pdf

TEIXEIRA, Elizabeth Nascimento et. al. Manual de Cuidados na Manutenção do Cateter Central de Inserção Periférica (PICC) Em Recém Nascidos Prematuros: Estudo de Validação, I6 $6^{\circ}$ SENPE 20II, Campo Grande MS. Acesso em I7 jul. 2021. Disponível em: http://www.abeneventos.com.br/i6senpe/senpe-trabalhos/files/oo54.pdf 23.

VIEIRA et al., CUIDADOS DE ENFERMAGEM EM PACIENTES NEONATOS COM CATETER CENTRAL DE INSERÇÃO PERIFÉRICA, Revista Eletrônica Gestão \& Saúde Vol. $04 \mathrm{n}^{\circ}$ 02, ano 2013 p. I88-99. Acesso em 17 jul. 2021. Disponível em: http://www.scielo.br/pdf/reeusp/v46n6/30.pdf. 